\title{
EL OBJETO DE LA SOCIOLOGIA. HECHO SOCIAL Y CONSECUENCIAS NO INTENCIONADAS DE LA ACCION
}

RESUMEN. La definición del objeto de la sociología ha cscilado entre versiones objetivistas (el hecho social de Durkheim) o versiones nominalistas (la teoría de la acción de Weber). A partir del dato de que el extrañamiento de la sociedad forma parte de la expericncia cotidiana de los actores se trata de fundamentar este extrañamiento -y el hecho social- en las consecuencias no queridas de la acción, distinguiendo así entre acción, acto y resultante. El objeto constitutivo de la ciencia social es así la situación, como resultante del entrelazamiento de consecuencias queridas o no de actos-acciones, objeto que legitima el punto de vista del sociólogo-observador. La función de la sociología es, pues, restablecer la transparencia colectiva en un mundo cuya diversificación hace que los actores no sepan lo que producen.

«Mais pour qu'il y ait fait social il faut que plusieurs individus tout au moins aient mèle leur action et que cette combinaison ait degage quelque produit nouveau» (Emile Durкheim, Les règles de la métbo de sociologique, París, 1968, p. XXII).

"Lo que quiere cada individuo es impedido por cada uno de los otros y lo que resulta es algo que nadie ha querido... Pero del hecho de que las diversas voluntades... no lleguen a obtener lo que desean, sino que se fundan en una media general, en una resultante común, no tenemos derecho a concluir que son iguales a cero" (K. MarX, carta a J. Bloch, 1855). 


\section{EL EXTRAÑAMIENTO DE LA SOCIEDAD $Y$ LOS ORIGENES DE LA SOCIOLOGIA}

\section{a) El becho social como constante}

Si hay algún punto en el que todos los sociólogos clásicos están de acuerdo es en el siguiente: que la sociedad funciona a todos los efectos como si fuera naturaleza. Las divergencias vienen después; a la hora de precisar qué se entiende por «naturaleza» (física, biológica, humana), qué quiere decir que «funciona como si» y sobre todo si esto es o no evitable. Algunas citas mostrarán esta esencial semejanza por encima (o por debajo) de la variedad de lenguajes:

«Amigos míos, somos cuerpos organizados; considerando como fenómenos fisiológicos nuestras relaciones sociales es como yo he concebido el proyecto que os presento» (Saint-Simon, Cartas de un babitante de Ginebra a sus contemporáneos, 1801).

«Por física social entiendo yo la ciencia que tiene por objeto el estudio de los '́enómenos sociales considerados con el mismo espíritu que los fenómenos astronómicos físicos, químicos o físiológicos, esto es, sujetos a leyes naturales invariables» (Comte, Plan de trabajos científicos necesarios para reorganizar la sociedad, 1822).

«El poder social, es decir, la fuerza de cooperación multiplicada que nace por obra de la cooperación de los diferentes individuos bajo la acción de la división del trabajo, se les aparece a esos individuos, por no tratarse de una cooperación voluntaria, sino natural, no como un poder propio, asociado, sino como un poder ajeno, situado al margen de ellos, que no saben de dónde procede ni a dónde se dirige y que, por tanto, no pueden ya dominar, sino que recorre, por el contrario, una serie de fases y etapas de desarrollo peculiar e independiente de la voluntad y de los actos de los hombres y que incluso dirige esta voluntad y estos actos» (Marx-Engels, La ideología alemana, 1845-46).

«Tan por completo está la sociedad organizada según el mismo sistema de un ser individual, que podemos percibir algo más que analogías entre ellos; la misma definición de la vida es aplicable a ambos. Unicamente cuando se advierte que las transformaciones experimentadas durante el crecimiento, la madurez y la decadencia de una sociedad se conforman a los mismos principios que las transformaciones experimentadas por agregados de todos los órdenes, inorgánicos y orgánicos, se ha llegado al concepto de la sociología como ciencia» (Spencer, Estática social, 1850).

«... no decimos que los hechos sociales son cosas materiales, sino que son cosas con el mismo título que las cosas materiales, aunque 
de otra manera» (Durkheim, Las reglas del método sociológico, 1895).

«Y, sin embargo, los fenómenos sociales son cosas y se les debe tratar como tales... es preciso estudiarlos desde fuera como cosas exteriores porque es así como se presentan a nosotros... Por consiguiente, al considerar los fenómenos sociales como cosas no hacemos más que obrar de acuerdo con su naturalezas (Durkheim, Las reglas del método sociológico, 1895).

«A juicio de Baxter, la preocupación por la riqueza no debía pesar sobre los hombros de sus santos más que como un manto sutil que en cualquier momento se puede arrojar al suelo. Pero la fatalidad hizo que el manto se trocase en férrea coraza. (...)

El ascetismo se propuso transformar el mundo y quiso realizarse en el mundo; no es extraño, pues, que las riquezas de este mundo alcanzasen un poder creciente y en último término irresistible sobre los hombres, como nunca se había conocido en la historia. La coraza ha quedado vacía de espíritu, quién sabe si definitivamente. En todo caso, el capitalismo victorioso no necesita ya de ese apoyo religioso, puesto que descansa è fundamentos mecánicos» (Weber, La ética protestante y el espiritu del capitalismo, 1916).

El tema de la sociedad como «organismo» o máquina, como «poder social extraño», como «petrificación mecanizada» o como «hecho social» es una constante, quizá la única constante en la historia de la sociología. Cabe rastrearlo hacia atrás, en El espíritu de las leves, de Montesquieu (1748); en los postulados nominalistas de la primera sociología anglosajona -en la que la sociedad es natural porque naturales son los hombres (Temple, Millar, Shaftesbury, Mandeville) ${ }^{1}-y$, antes aún, en el escepticismo de Montaigne - Pascal. Y puede también seguirse hacia adelante: en la teoría del lenguaje de G. H. Mead, la cosificación de Lukacs, el «se» en Ortega, lo prácticoinerte en Sartre, el sistema normativo en Parsons, el nivel biótico en la ecología humana, etc. Todos ellos captan, de un modo u otro, ese carácter fáctico y opaco de lo social que, sin ser empíricamente diferenciable de los individuos, posee una constancia que lo hace analíticamente diferente. Hay que darle la razón a Durkheim cuando escribe que la sociología

' Sobre los orígenes de la sociología en este nominalismo anglosajón, véase el excelente artículo de SombarT, desgraciadamente muy olvidado, «Los comienzos de la sociología", en Neosociología (IEP, Madrid, 1962, pp. 17 y ss.; 1." ed. en 1923). También, L. ScineIDER (ed.), The Scottish Moralists (The University of Chicago Press, Chicago, 1967); A. SWINGEWOOD, «Origins of Sociology: The Case of the Scottish Enlightment», British Journal of Sociology, XXI, 2 (1970), 64, y H. STRASSER, The Normative Structure of Sociology (Londres, 1976), cap. III: «The Case of the Scottish Enlightment». Volveremos sobre este tema inmediatamente. 
«no podía nacer más que el día que se hubiese presentido que los fenómenos sociales, por el hecho de no ser materiales, no dejan de ser cosas reales que exigen estudio. Para llegar a pensar que había motivo de investigar lo que son, era preciso haber comprendido que son de una manera definida, que tienen una manera de ser constante, una naturaleza que no depende del arbitrio individual y de la cual se derivan relaciones necesarias. También la historia de la sociología no es más que un esfuerzo por precisar este sentimiento, "profundizarlo", desarrollar todas las consecuencias que lleva consigo»" ${ }^{2}$.

Desde esta perspectiva, la historia de la sociología puede concebirse como la historia del devenir consciente del hecho social, pero también, y por lo mismo, la historia del hecho social mismo. El problema de si tal hecho social es anterior o no al nacimiento de la sociología con las revoluciones burguesas de Inglaterra y Francia, es decir, si las sociedades primitivas, tribales, tradicionales o los imperios antiguos estaban o no sometidos a esa facticidad es debatible, aunque todo apunta hacia una respuesta afirmativa (pues, en último término, estructuras de parentesco, lenguaje y técnicas poseen esa facticidad). Lo'que en todo caso no parece debatible es que su llegar a conciencia fue resultado del profundo proceso de renovación epistemológica (o, si se prefiere, de renovación de la etnociencia) que se produjo en Europa a partir del Renacimiento y que tuvo como efecto la progresiva separación cognitiva entre lo que comenzó a llamarse la Sociedad, el Estado y la Naturaleza, separación que es obra del pensamiento de la Ilustración; y que ese llegar a conciencia fue, a su vez, resultado de una serie de profundos cambios que alteraron la percepción del entorno social y su propia estructura objetiva.

\section{b) Diferenciación estructural y extrañamiento en la génesis de la sociología}

Desde finales del siglo xv a mediados del xvir, el desarrollo de los medios de comunicación (especialmente marítimos), el crecimiento del comercio y más tarde de la manufactura, la creciente división del trabajo y la urbanización, la formación de sociedades nacionales con lenguajes propios y, en general, la progresiva y acelerada diferenciación estructural ${ }^{3}$ y social generó poco a poco una sociedad que era desconocida a sus propios componentes, cada día más compleja y, por lo tanto, cada día más extraña. Al tiempo que

'E. Durkheim, Les règles de la métbode sociologique (Presses Universitaires de France, París, 1968), p. XXIII.

3 Sobre este concepto, véase T. PARsons, «Some Reflections on the Institutional Framework of Economic Development", en Structure and Process in Modern Societies (The Free Press, Glencoe, 1960), pp. 98.132. 
las relaciones sociales y económicas se ampliaban más allá de la «casa» (manor), hasta entonces esencialmente autosubsistente, para comprender la región primero, la nación más tarde, y la casi totalidad del mundo después, la antigua unidad social y europea del Sacro Imperio Romano-Germánico se escindía en grupos nacionales con Estados propios y diferenciados, lenguas y creencias religiosas distintas, ciudades cada vez más separadas del binterland rural y centros urbanos segregados, horizontalmente en grupos ocupacionales y verticalmente en clases sociales. La armónica unidad orgánica de la estructura social medieval es sustituida por una creciente diferenciación social, unificada casi únicamente por el intercambio y el comercio. Durkheim captó esta dinámica en De la división du travail social al postular el tránsito desde la solidaridad mecánica, basada en la semejanza y la fuerza de la conciencia colectiva, a la solidaridad orgánica, basada en la división del trabajo, la especialización y el intercambio ${ }^{4}$.

Pero en tales sociedades modernas fuertemente diferenciadas, cada sujeto y cada grupo sólo podía percibir una parte de la totalidad, ante la que surge, espontánea, la misma actitud de asombro y extrañamiento que ante los increíbles relatos de numerosos viajeros sobre el Nuevo Mundo, el Africa misteriosa o el lejano Oriente. Reflejándose en dichas sociedades a través de anecdotarios que iban desde lo fantástico a la etnografía, las sociedades nacionales europeas descubrieron su propia originalidad. Pascal se asombrará en 1670 ante el hecho de que

«tres grados de elevación hacia el polo arrojan al polvo toda la jurisprudencia. Un meridiano decide acerca de la verdad... Graciosa justicia que un río puede limitar. Verdad de este lado de los Pirineos, error del otro lado» ${ }^{5}$.

Y el barón de Montesquieu alcanza su primer éxito literario con las Cartas Persas (1721), imaginando que viajeros de ese país recorriendo Francia se asombran ante las costumbres e instituciones francesas, como los franceses lo hacen con las persas o las de los indios americanos. Nuestra propia sociedad comienza a ser tan extraña y ajena como cualquier otra. Somos extranjeros en nuestra propia casa.

La diferenciación estructural había hecho que los actores perdieran la perspectiva de la totalidad, y la creciente racionalización de la vida social complicará ésta, transformando a la sociedad en una máquina cuyo oscuro funcionamiento se desconoce:

${ }^{4}$ E. Durkherm, De la división du travail social (Presses Universitaires de France, París, 1960$)$. p. 214).

B. Pascai, Pensées, XXIV, iv (véase la edición de Losada, Buenos Aires, 1964, 
«La racionalización de la actividad comunitaria — dirá Weber- no tiene en absoluto por consecuencia una universalización del conocimiento relativo a las condiciones y relaciones de esta actividad, pues frecuentemente conduce al efecto opuesto. El "salvaje" sabe infinitivamente más de las condiciones económicas y sociales de su propia existencia que el "civilizado", en el sentido corriente del término, de las suyas» ${ }^{6}$.

El ritmo acelerado de cambio social, que seguirá en muchos campos una curva exponencial ${ }^{7}$ acelerando su ritmo hoy vertiginoso, acentuará la sensación de extrañamiento. La contraposición entre los clásicos y los novatores, entre la tradición y la modernidad, entre lo viejo y lo nuevo, surgirá pujante como esquema de división ideológico, marcando con una pátina de asombro la realidad generada día a día.

Pero el extrañamiento de la sociedad pronto dará origen a un nuevo matiz: ese ser extraño y misterioso que todos conformamos es, de hecho, un ser que actúa de ciertos modos y que tiene sus propias leyes. No las leyes del deber ser, extraídas de la naturaleza para regir a la sociedad, como querían los teóricos del Derecho Natural (desde Grotio en adelante), sino las leyes de la naturaleza, las mismas que Galileo descifra y que Newton sintetizará en los Principia. Por ello, la sociología surgirá, según demuestra Sombart, entre los adversarios de la teoría del Derecho Natural, en la generación siguiente a Hobbes, en la generación de Montesquieu. Althusser ha calificado a Montesquieu como un «precursor» de la sociologia que al definir las leyes como «relaciones necesarias que derivan de la naturaleza de las cosas», salta desde una concepción normativa de la sociedad (la ley como decreto del Soberano, sea éste Dios o el Monarca) a una concepción científica: la ley como encadenamiento de hechos naturales. Montesquieu, al «aplicar a cuestiones históricas y políticas una concepción newtoniana de la ley, concebida no como un orden ideal, sino como una relación inmanente entre fenómenos», está generando una drástica revolución teórica ${ }^{8}$.

Una ley interna parece aglutinar y cimentar los fenómenos sociales que se presenten encadenados y formando una totalidad. Y así es. Si la sociedad es un conjunto de individuos en interacción, de ello se deduce que, dependiendo del grado de interdependencia, un conjunto igualmente numeroso de individuos puede aglutinarse en más o en menos, puede ser más o menos

- M. Weber, Essais sur la théorie de la science (París, 1955), p. 397.

Así, por ejemplo, en relación con el crecimiento de la población, como ya señaló Malthus. Pero también, y esto es quizá más notable, en cuanto al desarrollo de la ciencia, que ha seguido un creciniento nítidamente exponencial; véase Derek PRICE, Science Since Babylon (Yale University Press, New Haven, 1961).

${ }^{*}$ Véase L. Althusser, Montesquieu, la politique t't l'bistoire (Presses Universitaires de France, París, 1959), p. 26. Una interpretación menos radical es la de R. Aron, quien considera a Montesquieu como «el último de los filósofos clásicos y el primero de los sociólogos. Véase Raymond Aron, Les étapes de la pensée sociologique (Gallimard, París, 1967), p. 66. 
sociedad. La diferenciación estructural de la sociedad europea a partir del Renacimienot da origen a un grado de interdependencia hasta entonces desconocido. Si algún galeón español cargado de plata es apresado por corsarios ingleses, ello no sólo afecta a los puertos españoles de Cádiz o Sevilla, sino también a las fábricas de tejidos en los Países Bajos o al comercio de especies con Oriente. La expulsión de los judíos españoles ha hecho sentir su impacto en la economía levantina, pero también en la de numerosas ciudades europeas. Por ello, al tiempo que la sociedad europea, cada vez más interdependiente, deviene más y más social, se genera la conciencia de su variabilidad, y de su extrañeza. La sociedad europea deviene Gesselschaft y, por lo mismo, ajena. $Y$ una ciencia nueva surge para cubrir esa laguna.

Por ello, la sociología surgirá por vez primera en el pensamiento ilustrado escocés del siglo xvin cuando, sobre la sensación de extrañamiento social, se proyecta de nuevo la idea de orden cósmico, idea de la que había sido separada por la teoría del contrato social. Con ello, la artificialidad del orden político y social, que fue el arma crítica de la Ilustración, es redescubierta en la nueva sociedad burguesa como orden divino, primero, y natural después. La aplicación del modelo científico a la sociedad tuvo, por ello, que esperar el triunfo de las revoluciones burguesas en Inglaterra y Francia, y a ese ritmo, con intervalos de medio siglo, surgirá la sociología, primero en Inglaterra a mediados del xvin, después en Francia a comienzos del xix. En este sentido, la causa estructural de la sociología (la diferenciación social y el extrañamiento) se fue gestando a lo largo del Antiguo Régimen, pero su base teórica, el punto de vista científico aplicado a lo social, sólo pudo surgir cuando, establecida la burguesía, la artificialidad de la sociedad es de nuevo negada. De ahí las dificultades de Kant y los neokantianos, atrapados aún en el dualismo que contrapone la determinación natural a la artificialidad social, para elaborar una verdadera ciencia de la sociedd.

Desde las universidades de Glasgow y Edimburgo, Reid, Monboddo, Ferguson y Smith repetirán la misma afirmación: la sociedad y sus instituciones son el resultado inconsciente y no previsto de las acciones humanas, recapitulando así dos siglos de historia europea. Pero, ciertamente, si tales resultados inconscientes y no previstos son positivos y beneficiosos, ello se debe a que son el producto de los instintos naturales de los hombres, instintos colocados por el Gran Director de la Naturaleza (A. Smith) o el Gran Geómetra (Reid) en nosotros. Por ello, todos recuperarán en tono moral la parábola cínica de Mandeville en la Fábula de las Abejas (1714): del mismo modo que, cada abeja, siguiendo su instinto natural, produce el mejor resultado para la comunidad, así los hombres, -movidos ciegamente por intereses egoístas, producen el mejor resultado colectivo. La mano de Dios guía cada acto personal hacia el mejor bienestar de todos: 
«Como cada individuo... se propone en la medida de lo posible emplear su capital para apoyar la industria doméstica y así dirigirla para que su producto sea del mayor valor, cada individuo necesariamente trabaja para que la renta anual de la sociedad sea tan grande como sea posible. El, usualmente, ni intenta promover el interés público, ni sabe en qué medida lo promueve... él sólo intenta su propia ganancia y, en esto, como en muchas otras cosas, es guiado por una mano invisible para promover un fin que no tiene parte en sus intenciones. Persiguiendo su propio interés firmemente prevalece el de su sociedad de modo más efectivo que cuando realmente intenta promoverlo. Nunca he conocido nada bueno hecho por quienes afectan comerciar por el bien público» ${ }^{9}$.

Y el modelo, de acuerdo con las propias indicaciones de Smith, se ampliará para cubrir una gran variedad de fenómenos, fuera ya del campo económico:

«En cada fase de la sociedad que ha existido, la multitud ha actuado en general desde los impulsos inmediatos de la pasión, o desde la presión de sus apetencias y necesidades; y así, lo que comúnmente llamamos un orden político es, por lo menos en una gran medida, el resultado de las pasiones y aperitos de los hombres combinados con las circunstancias de sus situaciones; o, en otras palabras, es fundamentalmente el resultado de la sabiduría de la naturaleza... Incluso en aquellos brutales períodos de la sociedad en que, como animales inferiores, sigue ciegamente sus principios instintivos de acción, es conducido por una mano invisible y contribuye parcialmente a la ejecución de un plan de cuya naturaleza y ventajas no tiene conocimiento. Las operaciones de la abeja... nos transmiten una imagen sorprendente de los esfuerzos del hombre» ${ }^{10}$.

Lo que me interesa de tales citas no es la divinización del liberalismo que implican, ya señalado por Gómez Arboleya ${ }^{11}$, sino la idea, teológicamente fundada, de que la sociedad es, en su totaldidad, el resultado no querido de las acciones humanas. Tan poco consciente es el sujeto, cada sujeto,

\footnotetext{
${ }^{9}$ A. Smith, The Wealth of Nations (Adam and Charles Black, Edimburgo, 1883), p. 199.

${ }^{10}$ Dugald Stewart, Collected Works (W. Hamilton Ed., Edimburgo, 1854), p. 227.

"Como escribía Gómez Arboleya: "Dios es más y más identificado con el orden na. tural, un orden que ha distribuido los bienes del mejor modo, para que cada trabajador tenga su existencia asegurada... Actividad privada egoísta, comercio sin trabas y armonía resultante son preceptos "naturales". En el reconocimiento de las libertades que pedía el burgués se manifiesta la comprensión exacta de la voluntad divina. Nunca el egoísmo privado alcanzará semejante sanción en la historia. Comercio e industria se hacen religión, y la religión, comercio $\mathrm{e}$ industria. Las actividades y pretensiones de una clase se cargan así de un ingente dinamismo.» Historia de la estructura y del pensamiento social (Instituto de Estudios Políticos, Madrid, 1957), p. 184.
} 
acerca del significado objetivo de su propia acción, que sólo Dios sabe lo que cada uno, de hecho, produce, y así, sólo en su Autoconciencia se restablece la transparencia colectiva. Sólo en El encuentran solución los misterios de la sociedad.

Pero la idea de que existía una lógica oculta detrás de la multiplicidad cambiante de la dinámica social y que tal secreto podía desvelarse analizando las consecuencias no queridas de las acciones de multitud de sujetos en interacción, era un gigantesco paso adelante, por mucho que su fundación derivara del pensamiento teológico. A partir de tal fundamento, la sociología podrá nacer, plena de sentido, tan pronto como la hipótesis teológica que fundaba el razonamiento social sea abandonada. Lo que no será tarea fácil.

Saint-Simon y Comte, los profetas de París, según acertada caracterización de F. Manuel ${ }^{12}$, secularizarán ese providencialismo divino en la ley de los tres estudios, que conduce a la humanidad a la sabiduría y la paz perpetua aprovechando también las pasiones humanas:

«En el desarrollo de las ciencias y las artes el espíritu humano sigue un curso predeterminado que es superior a la más poderosa fuerza intelectual, que aparecen sólo como instrumentos destinados a producir descubrimientos sucesivos en momentos determinados.

Aunque esta fuerza deriva de nosotros, no está más en nuestro poder escapar a su influencia o controlar sus acciones que cambiar a nuestro placer el impulso primitivo que hace a nuestro planeta girar alrededor del sol.

Sólo los efectos secundarios están sujetos a nuestra dependencia. Todo cuanto podemos hacer es obedecer esta ley (nuestra verdadera providencia) con comprensión, tomando en cuenta el curso que prescribe para nosotros, en lugar de ser ciegamente empujados por ella» ${ }^{13}$.

La mano invisible del pensamiento escocés del siglo XviII sufrirá así múltiples caracterizaciones: en la teoría del progreso positivista, en la astucia de la razón hegeliana, o en la dinámica del poder social extraño de Marx. En todas ellas el curso social vendrá determinado por poderes o instancias superiores, que garantizan el acuerdo de la dinámica colectiva $\mathrm{y}$, por ello, el final advenimiento de la Ciudad de Dios. Y, de este modo, el estudio de las consecuencias no queridas de la acción, que debía haber fundado la autonomía de la sociología como ciencia, fue oscurecido por una interpretación teleológica y teológica del providencialismo pseudosecularizado que

12 F. Manuel, The Propbets of Paris (Harvard University Press, Cambridge, 1962) y The New World of Henry Saint-Simon (University of Notre Dame, Indiana, 1963).

${ }_{13}$ Saint-Simon, citado en F. Manuel, The New World of Henry Saint-Simon, op. cit., p. 151 . 
concibe la historia como el oculto camino hacia la libertad, la felicidad y el orden, una orientación intelectual que, de seguir a Schneider, culminaría en el materialismo dialéctico, el funcionalismo y la teoría de sistemas ${ }^{14}$.

En todo caso, este metamodelo define ya una problemática básica del pensamiento social: que el sujeto, el actor, no acaba de captar el sentido objetivo de su propia acción. Este es el constituyente pragmático de la sociología. El extrañamiento social se extiende hasta cubrir la propia acción, cuyos últimos resultados y consecuencias se ignoran. La distancia que separa una aproximación objetivista de otra subjetivista en la sociología deriva de esta base: el actor es juguete de fuerzas que no conoce y el sociólogo será el encargado de restablecer la transparencia colectiva, rota a partir de la diferenciación estructural de las sociedades modernas. Por ello, se ha podido decir que «los fundadores de la sociología moderna galopaban sobre dos caballos, cada uno con su propia dirección» ${ }^{15}$, ya que, si en sus escritos trataron de desvelar el sentido objetivo de la historia, ello no era fácil de reconciliar con el protagonismo que se atribuían sus sujetos. Los hombres hacen la historia, dirá Marx, para añadir inmediatamente: «pero no saben lo que hacen». Como menores de edad, los ciudadanos de estas complejas máquinas que son las sociedades modernas necesitarán de un nuevo profesional que desvele el significado último de su prometeica laboriosidad.

Esta es la contradicción central que nuclea el pensamiento de los «fundadores». Hay así en Marx una tensión constante entre un modelo positivista y darwiniano, por un lado, y la teoría hegeliana de la reflexividad, por otro, que no acaba de dilucidar si la revolución tiene que ser concebida como una dinámica autónoma del sistema (objetivismo) o, por el contrario, como resultado de un proyecto humano (subjetivismo) que entiende, y por lo tanto, trasciende aquella legalidad impersonal ${ }^{16}$.

Tampoco Weber consiguió sintetizar el romanticismo de la Escuela Histórica y el cientifismo positivista neokantiano, y su metodología muestra a cada paso el gigantesco esfuetzo desarrollado en ese sentido ${ }^{17}$. Y nada sería más fácil que mostrar, por detrás del explícito objetivismo metodológico de Durkheim, el constante recurso (expreso o tácito) a los motivos individuales de la acción ${ }^{18}$ de modo semejante a como se quiebra en multitud de ocasio-

${ }^{14}$ L. Scineider, The Scoltish Moralists, op. cit., p. 1.

${ }^{15}$ R. H. Brown, «Symbolic Realism and Sociological Thought. Beyond the PositivistRomantic Debate», en R. H. Brown y S. M. Layman, Structure, Consciouness and History (Cambridge University Press, Cambridge, 1978), p. 16.

to Eso he tratado de mostrar en mi trabajo La teoría de la cosificación: de Marx a la Escuela de Frankfurt (Alianza Ed., Madrid, 1981), pp. 1 y 2, donde se citan trabajos de Albrecht Wellmer, Alfred Schmidt y Jacobo Muñoz en el mismo sentido.

17 Véase W. G. Runciman, A Critique of Max Weber's Pbilosopby of Social Science (Cambridge University Press, Cambridge, 1972).

${ }_{18}$ Véanse R. H. Brown, op cit., pp. 20-22, y J. D. Douglas, The Social Meaning of Suicide (Princeton University Press, Princeton, 1967). 
nes el explícito nominalismo metodológico de Weber ${ }^{19}$. Así, «en lo que parece haber acuerdo... entre todos los principales fundadores de la sociología es que los hechos sociales son, al tiempo, objetivos y subjetivos» ${ }^{20}$ y la dualidad aparente entre objetivismo y subjetivismo, entre realismo y nominalismo, entre estructura y acción, entre leyes y sentidos, recorre toda la sociología al tiempo constituyéndola y disolviéndola, como afirmación de sus metas unificadoras y como crítica de sus mediocres resultados.

La conciencia de un tal objeto, de un hecho social autónomo, se radicalizará a partir de las Revoluciones inglesa y francesa, poniendo de manifiesto que la dinámica social no es reconducible a la intención de sus agentes ${ }^{21}$. La sociología como ciencia social sólo pudo surgir a partir del momento en que devino consciente ( $y$, sin duda, también real) ese nuevo objeto distinto, tanto de la naturaleza (o siendo al menos una forma específica de naturaleza) como del individuo. Así, como han escrito Bourdieu, Chamboredon y Passeron:

«Es posible ver en el principio durkheimiano, según el cual hay que considerar los hechos sociales como cosas (se debe poner el acento en considerar cómo), el equivalente específico del golpe de estado teórico por el cual Galileo construye el objeto de la física moderna como sistema de relaciones cuantificables o de la decisión metodológica por la cual Saussure otorga a la lingüística su existencia y objeto distinguiendo la lengua de la palabra» ${ }^{22}$.

Resumiendo, la sociología nace como consecuencia de una quiebra, cada vez mayor, entre el ser social y la conciencia del ser social. Por un lado, el ser social se complica y diferencia, se entrelaza y parece ser un ser de algún tipo especial; por otro lado, la conciencia, que descubre la variabilidad de formas sociales y culturales, deviene al tiempo consciente de su ignorancia. La sociedad surge como algo específico y nuevo, al tiempo que los actores se asombran ante ese ser. Es esta contradicción la que dará origen a la indagación sobre la naturaleza de la sociedad.

Sobre esta base común, es decir, sobre la base de la aceptación del hecho social, que es el punto de partida mínimo de la sociología, las divergencias se acumulan. Se acepta que el objeto de la sociología, lo que la constituye como ciencia, es el dato del hecho social en cualquiera de sus variadas formas; se acepta también que existe una específica legalidad social

19 Véase H. H. Gerth y C. Wright Milis, From Max Weber (Oxford University Press, Nueva York, 1969), pp. 55-59.

${ }^{20} \mathrm{~J}$. Rex, Discovering Sociology (Routledge and Kegan Paul, Londres, 1973), p. 218.

"Así, sobre todo, en A. DE TOcqueville, El Antiguo Régimen y la Revolución (Guadarrama, Madrid, 1969), pero también en La democracia en América (Fondo de Cul. tura Económica, México, 1957).

${ }_{22}$ El oficio de sociólogo (Ed. Siglo XXI, Madrid, 1976; 1.* ed. francesa, 1973), p. 52. 
independiente de la legalidad que rige los comportamientos de los individuos; pero al mismo tiempo se reconoce ( $\mathrm{y}$ esto es lo que origina los problemas) que esa sociedad no tiene más existencia que la que le proporcionan sus sujetos (cuyo doble significado castellano es aquí revelador). El problema, pues, es el de determinar cuál sea la naturaleza de ese ser que sabemos es, cuál es la naturaleza de esa facticidad.

\section{LA REALIDAD SOCIAL: HECHOS SOCIALES Y CONSECUENCIAS NO INTENCIONADAS DE LA ACCION}

\section{a) El becho social como prenoción en Durkbeim y su desvanecimiento en la sociología contemporánea}

Nuestro problema es clarificar esta idea que parece ser constante en la sociología; que la realidad social posee un carácter objetivo y fáctico que la impone sobre los actores que le dan vida. Para decirlo con Mandelbaum, uno de los pocos que aún defienden este objetivismo clásico, nuestro objetivo es

«mostrar que uno no puede comprender las acciones de los seres humanos como miembros de una sociedad, a menos que asuma que hay un grupo de hechos, que llamaré "hechos sociales", que son tan primarios como los hechos que son de carácter "psicológico". Al hablar de los "hechos sociales" me refiero a cualquier hecho que concierna las formas de organización presentes en la sociedad. Al hablar de "hechos psicológicos" me refiero a cualquier hecho que concierna los pensamientos y acciones de seres humanos específicos ${ }^{23}$.

No es tarea simple. Marx no llegó a hacerlo, aunque la teoría del fetichismo de las mercancías se movía en esta dirección. Tampoco Durkheim - y esto es aún más revelador- llegó a mostrar la «realidad» del hecho social, y en Las reglas del método sociológico se limitó a postular su existencia, sin llegar jamás a preguntarse cómo es que los hechos sociales funcionan como cosas.

Comenzaré con una afirmación que, sin duda, va a ser aceptada sin dificultad: que el actor percibe el mundo social como una realidad externa y objetiva con la que tiene que contar para cualquier proyecto, por nimio que sea ${ }^{24}$. El punto de vista común acepta acríticamente y da por supuesto

${ }^{23}$ M. Mandelbaum, «Social Facts», en A. Ryan (ed.), The Philosopby of Social Explanation (Oxford University Press, 1972), p. 113.

${ }_{24}$ Esta afirmación puede ya encontrarse en Durkheim; véase Les règles de la méthode sociologique (Presses Universitaires de France, París, 1968), p. 53: «Nos es preciso considerar... los fenómenos sociales en sí mismos, separados de los sujetos conscientes que se los representan; es preciso estudiarlos desde fuera como cosas exteriores; porque es así 
este hecho, porque tal es el modo espontáneo de percibir lo social: como algo que está ahí que «se» hace o «se» dice, y con lo que hay que contar, para bien o para mal. Si la realidad es, como decía Maine de Biran, aquello que «resiste» la propia acción, no cabe duda que la sociedad «resiste» y "se» resiste, por lo que cabe afirmar que es algo real. Así, pues, que contra el actor y sus deseos se halla la sociedad con sus mandatos e imposiciones, no es, digámoslo de entrada, ningún descubrimiento sociológico especial, sino simplemente la reproducción del modo común de percibir el mundo social. La ciencia social refleja aquí simplemente la etnociencia.

Por ello, si la idea de Durkheim al postular que los hechos sociales son cosas fue la de superar las «nociones comunes» y los «idola» ${ }^{25}$, se engañó a sí mismo, pues tal punto de partida es también un idola, concretamente, y según Bacon, un idola for ${ }^{26}$. Es más, si la tesis de Durkheim, a pesar de la reacción crítica que inicialmente produjo, alcanzó aceptación general, ello se debió precisamente a esto: reafirmaba el modo común de percibir el mundo social. Los sociólogos aceptaron esta noción de sentido común y la elevaron, quizá inconscientemente, al rango de experiencia constitutiva de la sociología. Como tal, fue asimilada como presupuesto tácito, incluso por quienes estaban en desacuerdo con el idealismo radical de Las reglas del método sociológico, y a pesar de la propia declaración de Durkheim de que, sin una definición clara del hecho social, la sociología jamás podría ser una ciencia.

Infundado objetivismo que armonizaba perfectamente con el naturalismo positivista y se hallaba, pues, de acuerdo con las tendencias dominantes de la filosufía de la ciencia y de la metodología; sólo la tajante separación entre el observador y lo observado (en este caso entre el actor y la sociedad) garantizaba el modelo de la ciencia natural (bien la mecánica o la biología). Aunque ello implicara reducir el actor al nivel de la propia facticidad, frente al punto de vista del observador-científico que, milagrosamente, conseguía sacar su cabeza fuera de ella. Una sociología «por la ranura» (Adorno) ${ }^{27}$ que al tiempo que objetivaba al actor -y por lo tanto al propio sociólogo como actor- extraía al observador del mundo de la facticidad y lo colocaba frente a ella para garantizar así una metodología científica. El dualismo entre el actor y la sociedad pasaba entonces a ser el dualismo entre el científico social y la sociedad, base de la ciencia ${ }^{28}$. Aquél devenía

como se presentan a nosotros.» Véase, también, A. Schutz, Collecied Papers. I. The Problem of Social Reality (Martinus Nijhoff, La Haya, 1973), pp. 329 y ss.

${ }^{25}$ E. Durkнeıм, Les règles de la méthode sociologique, op. cit., pp. 31-34.

20 Véase F. BACON, Novum organum, parágrafos 38 a 68 y, sobre todo, el parágrafo 43 : «las palabras son impuestas a las cosas según la concepción del vulgo, por lo cual la necia y desacertada imposición de nombres estorba enormemente el entendimiento».

${ }^{27}$ Véase T. Adorno, Dialéctica Negativa (Taurus-Cuadernos para el Diálogo, Madrid, 1975), pp. 142 y ss.

${ }_{28}$ Véase, sobre esto, mi trabajo Juicios de valor y ciencia social; una critica interna del civalorismo (Fernando Torres Ed., Valencia, 1975), pp. 21-24. 
la única conciencia en un mundo de hechos, la propia autoconciencia social. Que esta argumentación debía conducir al profetismo es una sospecha teórica que los hechos, desde Saint-Simon a Comte, desde Marx a Weber, parecen confirmar. Así, y paradójicamente, la sociología, afirmando, por supuesto, que debía ser construida en contra de las apariencias, las nociones vulgares y los idola, olvidó que la facticidad social era una de esas nociones vulgares y basó en dicho olvido su propia fundamentación.

Contra esta aceptación acrítica del sentido común y la consiguiente reducción sociologista del actor ${ }^{29}$, sólo la tradición marxista parecía dis. poner de utillaje crítico, concretamente la tradición que, partiendo del capítulo sobre «El fetichismo de las mercancías» del volumen I de El capital, se extiende hasta Lukacs o Korsch, como teoría de la «segunda naturaleza» social cosificada del hombre. Pero aquí también la fuerza del positivismo fue tal que, comenzando por el propio Marx y continuando con Engels y los comentaristas, tanto socialdemócratas (Kautsky) como comunistas (Plejanov, Bujarin), acabó reduciendo el desarrollo histórico a dialéctica interna de la propia naturaleza ${ }^{30}$. En el fondo era un positivismo aún más radical que el de Durkheim, pues si bien éste trazaba al menos una línea entre naturaleza y sociedad, no así el marxismo clásico, que se encontró siempre con el grave problema de explicar cómo era posible la reflexión de la sociedad a través de la ciencia social en un mundo natural. Si la facticidad social no era sino uno más de los fenómenos de la dialéctica de la evolución natural, que de la materia inanimada produjo la animada, de ésta la vida, de la vida los mamíferos, de quienes el mono, de quienes el hombre, de quienes la sociedad primitiva ${ }^{31}$ y así, indiferente a toda intervención humana reflexiva, hasta la sociedad capitalista y de ella a la socialista, la facticidad quedaba sobradamente fundada y carecía de misterios. El único misterio era la posible trascendencia humana de ese impenetrable orden natural.

La teoría de la cosificación, tal y como fue formulada por Lukacs, parecía ofrecer una salida al problema. En ella la facticidad resultaba derivar directamente del modo de producción capitalista y la ingente racionalización, cuantificación y mecanización de la vida que éste impone. Desgraciadamente, y como habría de reconocer el propio Lukacs en la autocrítica de Historia $y$ conciencia de clase, la cosificación era concebida de un modo tan total y abso-

${ }^{29}$ Me refiero a lo quie, desde Dennis Wrong, se denomina «concepción sobresocializada del sujeto». Véase D. WRONG, "The Oversocialized Conception of Man in Modern Sociology", en S. G. MacNall, The Sociological Perspective (Little Brown and Co., 1971), pp. 120 y ss. En relación con cierto tipo de interaccionismo simbólico, véase D. L. CAkVETH, "The Disembodied Dialectic: A Critique of Sociological Relativism», Theory and Society, 4, 1 (1977), 81.

${ }_{30}$ El texto clásico en este sentido es el de H. Marcusse, El marxismo soviético (Alianza Ed., Madrid, 1968). He tratado el mismo tema en mi libro La teoria de la cosificación: de Marx a la Escuela de Frankfurt, op. cit.

"Plagio aquí, descaradamente, a A. García-Calvo, Apotegmas sobre el marxismo (La Banda de Moebius, Madrid, 1977), p. 7. 
luto, que la eventual retrocapción de la alineación en el sujeto resultaba ser un momento mítico. Lukacs hizo del mundo social una «cosa» tan absoluta y omnipotente, que sólo postulando un actor igualmente mítico, el Proletariado y, en su nombre, el Partido, podía ser disuelta. La Teoría Crítica absolutizó, más que matizó, la cosificación de la cosificación lukacsiana, conduciendo el pensamiento crítico a la desesperanza y el apartamiento del mundo ${ }^{32}$. Línea teórica, toda ella, que era también reproducción de una experiencia de sentido común: la de la impotencia del intelectual para generar un movimiento social revolucionario; la de la desesperanza de la clase obrera confrontando cotidianamente un capitalismo cada día más pujante.

Frente a este objetivismo poderoso, que se imponía tanto sobre aquellos que lo aceptaban como sobre quienes, angustiadamente, trataban de rechazarlo, el nominalismo weberiano no ofrecía alternativa ${ }^{33}$. De entrada, por su carácter puramente teórico. Es ya un lugar común que mientras Weber mantuvo una postura resueltamente nominalista en sus análisis metodológicos, en los estudios sustantivos la facticidad social era afirmada con tanta fuerza como en la propia tradición marxista ${ }^{34}$; y fueron estos análisis precisamente (en la teoría de la racionalización y burocratización del mundo) los que alimentaron el pesimismo de la Escuela de Frankfurt. Además, difícilmente podía aceptarse el contractualismo social que el nominalismo metodológico parecía imponer cuando la experiencia cotidiana mostraba sin duda su falsedad. Era necesario otro contexto social para que el nominalismo pudiera ser una fructífera teoría social. Ese contexto lo ofrecían, en los años veinte y treinta, los países anglosajones.

Comenzando con el pragmatismo de Dewey y Mead ${ }^{35}$ y con la posterior recepción de Weber ${ }^{36}$ en Estados Unidos a través de la sesgada traducción parsoniana, y continuando después con la tradición individualista del interaccionismo simbólico (que abarca desde H. Blumer a M. Kuhn) y la recepción

3. Me refiero al cap. III de mi libro La teoría de la cosificación: de Marx a la Escuela de Frankfurt, op. cit.

33 Véase el cap. I de Economía y Sociedad (Fondo de Cultura Económica, México, 1969).

${ }_{34}$ La primera afirmación en este sentido la hacen H. GerTh y C. Wright Milis, en From Max Weber (Oxford University Press, Nueva York, 1969), pp. 55-59.

${ }^{35} \mathrm{Y}$ ello al margen de las (posibles) interpretaciones de la obra de George Herbert Mead; véanse Chasin, «G. H. Mead: A Social Psychologist of the Moral Society», Berkeley Journal of Sociology, IX (1964), 95; H. BLumer, "Comments on Mr. Chasin's Articule», Berkeley Journal of Sociology, IX (1964), 118; H. Blumer, Simbolic Interactionism. Perspective and Metbod (Prentice Hall Inc., Englewood Cliffs, Nueva Jersey, 1969), y mis trabajos "Libertad y necesidad en la ciencia social; la aportación de G. H. Mead" y (en colaboración con Julio CARABAÑA) «Resumen y valoración crítica del interaccionismo simbólico", ambos en J. Jiménez Blanco y C. MOYA (eds.), Teoría sociológica contemporánea (Tecnos, Madrid, 1978), pp. 322 y 277, respectivamente.

${ }^{36}$ Sobre la interpretación de Weber efectuada por A. Schutz, véase R. J. Berstern, The restructuring of Social and Political Theory (Harcourt Brace Jovanovitch, Nueva York, 1976), pp. 136-156; B. Hindes, Pbilosopby and Metbodology in the Social Sciences (The Harvester Press, Sussex, 1977), pp. 49-78, y J. JimÉnez Blanco, «Weber, Schutz y Garfinkel sobre racionalidad», en J. Jiménez Blanco y C. Moya (eds.), Teoría sociológica contemporánea, op. cit., p. 366. 
fenomenológica o en la etnometodología, la realidad social es concebida no como hecho social dado, sino como resultado de la construcción y creación cotidiana de actores que interactúan. Con ello, el tema de la facticidad social será relegado a un discreto segundo plano o rechazado lisa y llanamente, en favor de una teoría sociológica de la acción.

El desarrollo consecuente del nominalismo ha conducido, sin embargo, a la casi total desaparición de la problemática del hecho social. Así, por ejemplo, H. Blumer afirma que "los "mundos" que existen para los seres humanos están compuestos de "objetos"... y dichos objetos son el resultado de la interacción simbólica» ${ }^{37}$. P. Berger y Th. Luckman escriben que «la lógica de las instituciones... no radica en la institución y funcionalidad externa, sino en el modo como son tratadas en la reflexión sobre ellas» ${ }^{38}$. Y más enfáticamente, A. Schutz escribía:

«Bajo el término "realidad social" quiero entender la suma total de objetos y sucesos en el mundo social cultural según son percibidos por el pensamiento de sentido común de los hombres viviendo sus vidas cotidianas entre contemporáneos y conectados con ellos en múltiples relaciones de interacción» ${ }^{39}$.

Sin duda, Schutz afirma igualmente que parte de esta experiencia cotidiana de sentido común es la experiencia de la facticidad social, pero nada más. Lo que queda es lo que está desde el principio y que es difícilmente negable: que los hombres perciben así su vida social.

El último paso en esta reciente reacción contra el objetivismo clásico lo ofrece la etnometodología, al menos en algunas de sus variantes: «nuestra preocupación con el "orden" es sólo y específicamente con cómo éste es hecho visible y así "creado" para la acción práctica, a través de las prácticas»" ${ }^{40}$. El orden sólo existe en la medida en que es creído y, por lo tanto, creado por los propios actores que así lo perciben.

Hemos pasado así en pocos años desde la acrítica aceptación de la facticidad social a su total rechazo. La sociología no se basaría ya en el hecho social; al contrario, su objeto de investigación sería cómo y por qué los actores construyen diariamente la realidad social fáctica por los procedimientos y modos que utilizan para dar cuenta, relatar, interpretar y dar sentido a la misma

${ }^{17} \mathrm{H}$. Blumer, Symbolic Interactionism, op. cit., p. 10.

${ }^{38}$ En The Social Construction of Reality (Doubleday Anchor Books, Nueva York, 1966; hay traducción en Amorrortu), p. 64.

${ }^{39}$ A. Schutz, «The Problem of Rationality in the Social World», en D. Emmes y A. Macintyre (eds.), Sociologica! Theory and Philosophical Analogies (The Macmillan Co., Nueva York, 1970), p. 5.

${ }^{*}$ La cita es de D. H. Zimmermand y D. J. Wieder, «Ethnomethodology and the Problem of Order», en J. P. Douglass (ed.), Understanding Everyday Life (Aldine Pub. Company, Chicago, 1970), p. 293. 
realidad social. Si la facticidad existe es porque los actores creen en ella y la construyen. Como ha escrito Peter Dreitzel, sintetizando esta perspectiva:

«Desde el punto de vista del paradigma interpretativo (una categoría elaborada por Wilson ${ }^{41}$ y que subsumiría el interaccionismo simbólico, la sociología fenomenológica y la etnometodología, E.L.E.), la estructura social se basa en los procedimientos interpretativos de los miembros intraactuantes de la sociedad... La realidad social en que la gente vive sus actividades cotidianas está construida no en los hechos "objetivos" de la situación, sino en las definiciones "subjetivas" de la situación... Bajo el paradigma interpretativo, toda la realidad social es percibida como resultado de procesos de negociación en marcha» ${ }^{42}$.

Quiero decir de entrada que estimo que esta reacción tiene aspectos enormemente positivos, especialmente comparada con el viejo positivismo naturalista o marxista. En primer lugar, porque implica desreificar la facticidad, considerándola como una mera posibilidad y no como un punto de partida necesario, algo, pues, que puede darse o no, y en diversa medida ${ }^{43}$. Además, allana el camino para cuestionar los mecanismos sociales a través de los que la facticidad social es generada. De este modo, la sociología, retornando sobre sí misma y criticando sus hipótesis básicas, consigue transformar un viejo presupuesto implícito en un tema de investigación empírica.

Sin embargo, es necesario también reconocer que esta autocrítica es injusta con la tradición que analiza; en primer lugar, con el marxismo o, al menos, con ciertas ideas y modelos de nivel medio que se deducen de él.

\section{b) Las consecuencias no intencionadas de la acción: de B. Mandeville a K. Popper}

Así, nadie quería producir el capitalismo moderno; sin embargo, éste surgió como consecuencia no querida del desarrollo tecnológico, de la evolución del comercio, el transporte y las fiananzas, como consecuencia de la alianza entre la burguesía y la Corona, etc. Ya dentro del modo de producción capitalista, los empresarios buscan sólo su propio beneficio, pero esto genera como respuesta los sindicatos, que controlan el mercado de trabajo, y entre unos y otros el capitalismo es sometido a una dinámica histórica a través

"T. P. WiLson, «Normative and Interpretative Paradigms in Sociology", en J. P. DougLaSs (ed.), Understanding Everyday Life, op. cit., pp. 57 y ss.

${ }^{42}$ P. Dreitzel (ed.), Recent Sociology no. 2. Patterns of Communicative Bebavior (The MacMillan Co., Nueva York, 1970), pp. XII-XIII.

${ }^{43}$ Véase, en este sentido, J. M. Maravall, "Descosificando el mundo: los límites del análisis fenomenológico», en J. Jiménez Blanco y C. Moya (eds.), Teoría sociológica contemporánea, op. cit., p. 358. 
de la lucha de clases que eventualmente generará la sociedad socialista a través de crisis económicas, resultado de la competencia a degüello, competencia y crisis que nadie quiere.

Por ello, Popper ha podido decir, sin duda con acierto, que Marx

«fue uno de los primeros en analizar las consecuencias no queridas de las actuaciones voluntarias de la gente actuando en una situación social concreta. Marx dijo, definitiva y claramente, que el capitalista está tan atado con la red de la situación social (o del "sistema social") como el obrero; que el capitalista no puede evitar el actuar del modo en que lo hace: está tan determinado como el obrero y los resultados de sus acciones son, en gran medida, inintencionados» ${ }^{44}$.

Por ello, ni la acción es reducible a su sentido subjetivo, ni las instituciones son lo que de ellas se piensa, pues hay siempre algo más, la lógica inconsciente de la sociedad que constantemente produce consecuencias, no queridas quizá, incluso no deseadas, pero que tienen que ser aceptadas como hechos que no derivan de nadie, hechos sin actor que los produce, hechos sociales propiamente dichos. Hay, por ello, una «segunda naturaleza», producto humano sin duda, pero independiente de todo deseo o voluntad. La facticidad es aquí concebida, también como resultado de la acción, pero no como resultado imaginario, sino real (y no sólo como resultado, sino también como presupuesto; esto lo veremos más adelante).

Popper estima que Marx fue uno de los primeros en plantear el tema de las consecuencias no queridas de la acción. Esto requiere una matización seria. De entrada porque, como ya vimos en el apartado anterior, la primera formulación explícita del tema de las consecuencias no queridas de la acción se encuentra en el pensamiento escocés del siglo xvirI y es, sin duda, de él, a través de A. Smith y Hegel, de donde pudo tomarlo Marx. Además, porque Marx jamás desarrolló explícitamente tal teoría y allí donde lo hace -en los Grundisse, al analizar el mercado como resultante de un paralelogramo de fuerzas - critica explícitamente el modelo ${ }^{45}$. Lo importante, dice ahí, es que las fuerzas que intervienen están ya socialmente determinadas. La facticidad es, para Marx, más bien presupuesto de la acción, que resultante de la misma. Finalmente, porque - como afirmaba Merton en un conocido trabajo- - «en alguna de sus numerosas formas, el problema de las consecuencias no queridas de la acción finalista ha sido tocado prácticamente por toda contribución sustantiva a la larga historia del pensamiento social» ${ }^{46}$, y

${ }^{44}$ K. Popper, Conjectures and Refutations (Routledge and Kegan Paul, Londres, 1963), p. 125 ; véase, también, p. 342 . El subrayado es mío.

45 He analizado este modelo (basándome en Engels y Althusser) en La teoría de la cosificación, op. cit., cap. III.

${ }^{46}$ R. K. Merton, Sociological Ambivalence and other Essays (The Free Press, Nueva York, 1976), p. 145. 
menciona concretamente los siguientes nombres: Maquiavelo, Vico, Smith, Marx, Engels, Wundt, Pareto, Weber, Walras, Cooley, Sorokin, Gini, Chapin y Von Schelting, lista que, como veremos, es incompleta y sesgada.

Efectivamente, la primera mención de esta idea se encuentra en la escolástica tardía española, concretamente en la obra de Luis de Molina, De Iustitia et Iure, al menos si aceptamos las opiniones de Von Hayek, sin duda quien más atención ha prestado recientemente a esta cuestión ${ }^{47}$. Es, sin embargo, el médico de origen holandés, erasmista y discípulo de Descartes y Hobbes, Bernard Mandeville quien usualmente recibe crédito por ello ${ }^{48}$. En su primer poema, The Grumbling Hive: Or, knaves Turn'd Honest (1705), ampliado y explicado más tarde en la conocida fábula de las abejas, The Fable of the Bees: Or, Private Vices, Publick Beneficts (1714), como en otras obras menores, como A Modest Defense of Publick Stews (1724), la moral era la misma: cuando los ciudadanos creen practicar la virtud producen la pobreza y la miseria colectiva; por el contrario, el lujo, el orgullo, la avidez, la vanidad y la avaricia estimulan la laboriosidad colectiva y el comercio. Si una nación restringe su consumo de bienes de lujo, conseguirá disminuir su prosperidad, pues los países exportadores de artículos de lujo no podrán importar las mercancías que esa nación produce, una tesis que podría haber inspirado a Sombart a escribir Lujo y capitalismo. La obra de Mandeville merece aún un estudio riguroso no sólo por ser un contrapunto a la tesis de Weber sobre el impacto del ascetismo protestante en la génesis del capitalismo, sino también porque es, a su vez, contrapunto a la tesis, machaconamente repetida por el funcionalismo, de Durkheim a Parsons, de que la sociedad es un ente moral; Mandeville, al contrario, piensa que los cimientos de la civilización no se encuentran en la virtud, sino en el vicio. Desconozco si Mandeville tomó estas ideas de Luis de Molina - lo que no dejaría de ser paradójico- o, más bien, se interpone un eslabón (como sugiere Horne): los moralistas franceses Montaigne y Pascal, que habrían sido leídos por Mandeville en sentido contrario, transformando el pesimismo moral de éstos en cínico optimismo $^{49}$. Lo que en todo caso es, sin duda, cierto es que la Fábula de las Abejas tuvo un enorme impacto en su tiempo. El obispo Berkeley la denunció por libertina y Hutcheson criticó la reducción de la solidaridad social al

${ }^{47}$ F. vON HAYEK, «The Results of Human Action but not of Human Design», en Studies in Philosophy, Politics and Economics (Routledge and Kegan Paul, Londres, 1967), pp. 97 y ss. Todo el resumen histórico que sigue está tomado de él, aunque ha sido ampliado.

${ }_{48}$ Véanse F. von Hayek, «Dr. Bernard Mandeville», en Now Studies in Pbilosopby, Politics, Economics and the History of Ideas (Routledge and Kegan Paul, Londres, 1978), pp. 249 y ss.; L. SchneIDER, The Sociological Way of Looking at the World (McGrawHill Book Co., Nueva York, 1975). Sobre B. Mandeville puede verse J. C. Maxwerl, «Ethics and Politics in Mandeville», Philosophy, 21 (1951), 242. De la Fábula de las Abejas hay una edición a cargo de F. B. Kaye, Clandon, Oxford, 1957.

${ }_{49}$ Véase A. Horne, The Social Thought of Bernard Mandeville (Columbia University Press, 1978), cap. III: «Mandeville and the French Moral Tradition», donde alude sobre todo a dos ensayos de Montaigne: «De la vanidad» y «Lo útil y lo honroso». 
egoísmo, pero ejerció un notable influjo en el liberalismo de A. Smith ${ }^{50}$, y fue citada por Voltaire, Hume y Rousseau.

A partir de ellos, la línea de desarrollo deviene más sinuosa. Por un lado, la idea pasó a Montesquieu, Hegel y Marx, pero fue también aceptada por la filosofía política contrarrevolucionario inglesa, especialmente por E. Burke, de quien la tomó la filosofía jurídica alemana en su lucha contra la codificación (especialmente Savigny). Fue a través de Ahrens, seguidor de la escuela histórica alemana, como llegó a Menger, quien la introduje de nuevo en el campo de la economía ${ }^{51}$ en 1883. Y fue de Menger de quien la tomó Von Hayek en un trabajo publicado en 1942, de donde la tomó, a su vez, Popper en 1944, quien la ha aceptado en La pobreza del bistoricismo, La sociedad abierta y sus enemigos, y diversos trabajos de filosofía de la ciencia social, a los que aludiré más adelante ${ }^{52}$.

Así, pues, se trata de una teoría enlazada con el pensamiento social conservador, debido, sin duda, al fácil desliz desde la afirmación fáctica de que las instituciones no son creaciones conscientes, al reconocimiento de su carácter «orgánico» considerándolas como el modo más «efectivo» y «natural» de regular los asuntos humanos ${ }^{53}$. Sin embargo, el cinismo de Mandeville es peligroso y lo mismo legitima que critica las instituciones existentes. Con el mismo argumento que justificaba el laissez-faire, abogaba en favor de los burdeles públicos, pues, como los tipos ideales de Weber, instituciones espontáneas las hay de las más variadas cataduras morales. Los resultados no queridos de la acción humana pueden evidentemente, ser positivos y beneficiosos, y lo serán, desde luego, si aceptamos con Smith que la invisible mano del Todopoderoso guía nuestros inciertos pasos en esta tierra. Pero los resultados pueden igualmente ser negativos; los puritanos querían simplemente servir al Señor, pero, según Weber, su ascetismo generó el capitalismo moderno, lo cual, probablemente, no les hubiera parecido muy valioso moralmente, como no se lo parecía a Weber. Por ello, la teoría tiene sentido científico y no meramente ideológico; porque apunta hacia un posible hecho cuya calificación moral vendrá, de venir, a posteriori.

De entre los sociólogos clásicos fue sin duda Weber quien primero aludió a la «paradoja de las consecuencias no intencionadas» o «la discrepancia entre lo que los hombres quieren y lo que resulta de su acción» ${ }^{54}$. Y en la reciente sociología de la desviación social, bien en el área de la enfermedad mental

${ }^{50}$ Sobre su influencia en A. Smith, véase N. Rosenberg, «Mandeville and Laisseztaire», Journal of the History of Ideas, 24 (1963), 183. También, VoN HAYEK, «Adam Smith's Message in Today Language», en New Studies, op. cit., pp. 267 y ss.

"Véase VON HAYEK, "The place of Menger's "Grundsatze" in the History of Economic Thougt", en New Studies, op. cit., pp. 270 y ss.

s2 K. Popper, "The Poverty of Historicism", Economica, XI, 3 (1944), 122, y The Open Society and its Enemies (Routledge and Kegan Paul, Londres, 1962). De ambas hay numerosas traducciones.

${ }^{53}$ Véase F. von Hayer, Studies in Pbilosophy, Politics and Economics, op. cit., p. 101.

${ }^{i 4}$ M. W'EBer, The Religion of China (The Free Press, Glencoe, 1951), p. 238. 
(Szasz, Scheff, Goffmann), o de la delincuencia (Shutherland, Cressey, Merton, Becker), son constantes las referencias a los mecanismos iatrogénicos de la terapia social que, creada para solucionar ciertos problemas sociales, de hecho contribuyen a su desarrollo ${ }^{53}$.

Son, sin embargo, pocos los autores que se han dedicado al tema explícitamente, y menos aún los que lo han considerado digno de recibir atención

«Es un error - dice Von Hayek-, al que expresiones poco meditadas de los científicos sociales a menudo dan apoyo, creer que su objetivo es explicar la acción consciente. Esta, si es que puede ser realizada, es una tarea diferente, la tarea de la psicología... El problema [que las ciencias sociales] tratan de contestar surge sólo en la medida en que las acciones conscientes de muchos hombres producen resultados no previstos, en la medida en que se observan regularidades que no son el resultado del diseño de nadie... Sólo en la medida en que cierto tipo de orden surge como resultado de la acción individual, pero sin ser prevista por ningún individuo, aparece un problema que exige una explicación teórica» ${ }^{56}$.

Así, pues, para Von Hayek, la ciencia social tiene su fundamento en las consecuencias no previstas de la acción. $\mathrm{Y}$ aunque las opiniones de K. Popper sobre la ciencia social no son fáciles de precisar, parece que coincidiría con Hayek. Así, con ocasión de la conocida dispura sobre el positivismo en la sociología alemana, Popper afirmaba:

«La sociología es autónoma en el sentido de que, en gran medida, puede y debe ser independiente de la psicología. Aparte de la dependencia de la psicología en ideas sociales, esto se debe al importante hecho de que la sociología se enfrenta constantemente con la tarea de explicar consecuencias no intencionadas y, a menudo, no deseadas de la acción humana» ${ }^{57}$.

Sin duda, el radical individualismo epistemológico de Von Hayek no debe confundirse con la posición más matizada de Popper, que, en principio al menos, es puramente metodológica. Por ello, mientras éste incluye dentro

"Véase L. SCHneIder, The Sociological Way of Looking at the World, op. cit., I y II. p. 39.

st F. von HayeK, The Countcr-Revolution of Science (The Free Press, Glencoe, 1952),

${ }_{57}$ K. Popper, «The Logic of the Social Sciences», en Adorno y otros, The Positivist Dispute in German Sociology (Heineman, Londres, 1976), p. 104 (hay traducción en Grijalbo). También, «Towards a Rational Theory of Tradition» y «Prediction and Prophecy», en Conjetures and Refutations, op. cit, pp. 120 y ss. (sobre todo 123-126) y 342 y ss. (hay traducción en Tecnos). Sobre esta distinción, véase K. J. Scotr, «Methodological and Epistemological Individualism», British Journal for the Pbilosophy of Science, 11 (1961), 331. 
de la ciencia social -e incluso en algún trabajo considera como el núcleo de la misma- el estudio de la «lógica situacional», el liberalismo radical de Hayek cierra el paso a toda indagación sociológica de la acción:

«Para las ciencias sociales - dice Hayek- los tipos de conciencia son datos, y todo lo que tiene que hacer con tales datos es ordenarlos convenientemente, de modo que puedan ser utilizados para sus tareas» ${ }^{58}$.

En qué medida la lógica situacional de Popper difiere del individualismo onto'ógico de Hayek, y en qué medida esas opiniones pueden ser sustentadas por sociólogos, es algo que no puedo discutir ahora. De momento, me interesaba recalcar la peculiaridad, rara vez destacada, de esta fundamentación ontológica de la sociología, basada en las dos siguientes ideas: 1) que los hechos sociales pueden ser la resultante inconsciente de las acciones; 2) que el objetivo de la ciencia social es, consecuentemente, comprender la facticidad social mostrando la mediación social que transforma acciones en resultantes. Modelo que objetivamente converge con el realismo de Durkheim, al que fundamenta ${ }^{59}$; de hecho, tanto Hayek como Popper tratan igualmente de evitar la ingenua creencia - de cuño spenceriano- de que la sociedad es resultante de acciones conscientes. Lo que Popper denomina «teoría conspirativa de la sociedad» y Hayek "constructivismo», formas (perversa y natural) del contractualismo social. $\mathrm{Y}$, en todo caso, lo que esta perspectiva parece imponer es un procedimiento y una definición. Un procedimiento: «comenzamos con las disposiciones individuales, información y relaciones, y trabajamos hacia afuera, hacia las consecuencias no queridas de la interacción” ${ }^{60}$. Y una definición: la acción es un tema, de ningún modo el tema de la sociología.

$\$ 8$ F. von Hayek, The Counter-Revolution of Science, op. cit., p. 39.

${ }^{59}$ En relación con esta posible convergencia entre el nominalismo inglés y el realismo francés, véase la teoría del «individualismo institucional» de J. Agsssı, «Institutional Individualism», Britisb Journal of Sociology, 2 (1975), 144; también, la teoría popperiana del «tercer mundo» desarrollada por I. C. Jarvie, Concepts and Society (Routledge and Kegan Paul, Londres, 1972). La teoría del «tercer mundo» puede verse en Objetive Know. ledge (Oxford University Press, Londres, 1972).

${ }_{00} \mathrm{~J}$. W. N. Watkins, "Ideal Types and Historical Explanation», en H. Feigl y M. Brodbeck (eds.), Readings in the Philosophy of Science (Appleton Century Crofts, Nueva York, 1953), p. 727. 


\section{ACTO, ACCION Y RESULTANTE: EL ENTRELAZAMIENTO DE LAS CONSECUENCIAS NO INTENCIONADAS}

Ahora bien, ¿dónde comienza y acaba una acción? Según Alfred Schutz, «estrictamente hablando, el actor, y sólo él, sabe lo que hace, por qué lo hace y dónde comienza y acaba su acción» ${ }^{61}$. Creo que esta opinión es más que dudosa. Sin duda, el actor interrumpe el seguimiento y observación de los resultados de su acción precisamente ahí donde la acción termina para él, es decir, ahí donde se consuma o frustra su propósito. Sin embargo, como ha indicado Von Wright ${ }^{62}$, habría que distinguir entre los resultados intencionados y las consecuencias no queridas del acto. Pues, como afirma Merton - -en una frase que es casi directamente la inversa de Schutz-, «estrictamente hablando, las consecuencias de la acción teleológica se limitan a aquellos elementos de la situación resultante, que son exclusivamente consecuencias de la acción, es decir, que no ocurrirían si la acción no hubiera tenido lugar» ${ }^{63}$.

Pero también dice:

«Con la compleja interacción que constituye la sociedad, la acción se ramifica. Sus consecuencias no se limitan al área específica en la que se pretende que se centren y se amplían a campos interrelacionados, explícitamente ignorados en el momento de la acción» ${ }^{64}$.

Pues efectivamente, más allá del punto, pragmáticamente determinado, en que el actor interrumpe el seguimiento de su acción, ésta genera consecuencias que pueden ramificarse y extenderse hasta el infinito. Tales consecuencias son indiferentes para el actor, por lo que no están incorporadas. en su evaluación de la acción; sin embargo, pueden ser importantes para un observador con un interés más amplio, sobre todo si le preocupa el posible encadenamiento objetivo de diferentes líneas de acción. Hablando en propiedad, la acción acaba donde el actor quiere, pero el acto no acaba ahí, y continúa produciendo consecuencias que, eventualmente, pueden ser relevantes para un observador e incluso para el mismo actor.

Es así erróneo decir - como Schutz- que «el término "acto" deberá designar el resultado del proceso en marcha de la acción, esto es, la acción consumada» ${ }^{65}$, puesto que la acción consumada y la resultante de la acción

"1 A. Schurz, "The Problem of Rationality in the Social World», op. cit., p. 13.

62 G. H. von Wright, Norm and Action (The Humanities Press, Nueva York, 1963), pp. $39-41$.

${ }_{63}$ R. K. Merton, Sociological Ambivalence, op. cit., p. 146.

${ }^{64}$ Ibidem, p. 154.

"Schutz, "The Problem of Social Reality», op. cit., p. 67. Más tarde, Schutz repite la misma idea: al proyectar una acción imaginamos «el resultado de esta acción futura, el acto imaginado como ya realizado» (p. 68), identificando de nuevo el proyecto con el resultado. 
de ningún modo tienen por qué coincidir (aunque, sin duda, podrían hacerlo). Schutz confunde acto y acción. El término acto alude a la conducta considerada objetivamente, al margen, por lo tanto, de la subjetividad, conciencia, intereses o deseos del actor; la acción, por el contrario, sólo puede concebirse como plasmación externa u objetivación de un propósito. $\mathrm{O}$ dicho en lenguaje weberiano, la acción tiene un significado subjetivo, el que el actor le otorga, mientras que el acto tiene un significado objetivo, el que descubre un observador con conocimiento e información más extenso que el del actor. No es, pues, cierto que el actor social, como afirma Rezsohazy, «es el autor individual o colectivo de los hechos sociales» ${ }^{66}$, si por «autor» entendemos no el causante, sino en su sentido subjetivo. El actor es causante de todas las infinitas resultantes que puedan derivarse de su acción, pues - como afirman los juristas - la causa de la causa es causa de lo causado. Pero sería forzar el lenguaje el considerarlo autor de aquello que, a lo mejor, jamás quiso, ni pensó, ni deseó causar. En última instancia, se es autor de lo que se quiere producir y de nada más, y se es quizá responsable de todas aquellas consecuencias de la acción que pudieron, presumiblemente, ser previstas en el momento de la acción. Pero más allá de la intención del actor e incluso más allá de la responsabilidad objetiva que se le puede atribuir, cabe que existan consecuencias objetivas, consecuencias inconscientes de la acción.

Esto muestra algo importante: no es necesario, como quería Marx, que las acciones estén previamente determinadas para explicar la facticidad social. Todo lo que necesitamos suponer es que, como dice Popper, «nada ocurre nunca exactamente como se quiso» ${ }^{67}$, afirmación que tiene buena base empírica. Ningún actor puede nunca ser totalmente consciente de todas las consecuencias de su acción. Esto es, creo, todo lo que necesitamos para dar cuenta del hecho social. $\mathrm{Y}$ propongo que denominemos resultantes a todas las consecuencias no previstas y/o no queridas que derivan de una acción.

Ahora bien, es lugar común afirmar que las acciones se entrelazan y encadenan formando líneas interdependientes que constituyen la trama social, es decir, dando origen a roles, instituciones y, en última instancia, a la estructura social. Lo que, sin embargo, rara vez se considera es que también las resultantes inconscientes de las acciones - especialmente de las acciones pautadas o típicas- pueden encadenarse, originando una trama social de resultantes. Veamos algunos ejemplos de micro y macrosociología, respectivamente.

Puede, por ejemplo, ocurrir que alter paute su acción tomando en cuenta las resultantes de la acción de ego, más que la acción misma. Se origina así

to R. Rezsohazy, Theorie et critique des faits sociaux (La Rennaissance du Livre, Bruselas, 1971), p. 35 .

67 K. Popper, Conjectures and Refutations, op. cit., p. 124. 
lo que Turner ha llamado sistemas de bábitos entrelazados, cuando «un miembro pauta su comportamiento para que se ajuste a las regularidades pasadas del comportamiento del otro" ${ }^{68}$, de tal modo que el encadenamiento de resultantes pasa a ser el sustrato oculto de una situación. Estos encadenamientos de hábitos se generan frecuentemente en relaciones familiares, donde cada miembro conoce las rutinas de los demás, organizando su propia acción en base a ellas. En este caso, alter se ajusta a ego, pero ego ignora dicho ajuste.

Sin embargo, puede también darse el caso de que las acciones de ego $\mathrm{y}$ alter se entrelacen de un modo inconsciente para ambos. Popper ofrece un ejemplo especialmente relevante:

«La competencia es un fenómeno social que usualmente no desean quienes compitan, pero que puede y debe ser explicado como una consecuencia (normalmente inevitable) no querida de acciones (conscientes y planificadas) de quienes compiten. Así, aunque podamos explicar psicológicamente algunas de las acciones de los competidores, el fenómeno social de la competencia es una consecuencia, psicológicamente inexplicable, de dichas acciones» ${ }^{69}$.

Los ejemplos de este entrelazamiento oculto de acciones que pasan a formar parte del sustrato - usualmente inconsciente para el actor- de una situación podrían multiplicarse:

- Según M. Duverger ${ }^{70}$, el sistema bipartidista inglés se debe simplemente al hecho de que los miembros del Parlamento son elegidos, por mayoría simple y en una sola votación, en distritos electorales con un solo representante. Estas reglas no se establecieron para crear un sistema bipartidista; son el resultado histórico del interés de los políticos tratando de maximizar su poder monopolizando puestos gubernamentales, y del interés de los electores en maximizar su influencia sobre los candidatos elegidos. Es, sin embargo, una de las instituciones centrales del sistema político británico.

- Según la teoría mertoniana de la anomia ${ }^{71}$, las diferentes formas de conducta desviada son modos diversos de adaptarse a una contradicción estructural, ella misma consecuencia no querida de muchas acciones. De una

${ }^{68}$ R. H. Turner, «Role-Taking: Process vs Conformity», en A. K. Ross (ed.), Human Behavior and Social Processes (Houghton Mifflin Co., Boston, 1962), pp. 20 y ss. La cita es de la p. 35.

${ }^{69}$ K. POPPER, «The Logic of Social Sciences», op. cit., p. 102.

${ }^{70}$ M. Duverger, Political Parties (Methuen, Londres, 1954), pp. 216-218; también, M. LENOFF, The Structure of Social Science (G. Allen and Unwin, Londres, 1974), pp. $81-82$.

"R. K. Merton, «Anomie and Social Structure», en Social Theory and Social Structure (The Free Press, Glencoe, 1957; hay traducción en el Fondo de Cultura Económica). 
parte, la internalización de objetivos y valores que enfatizan el éxito social, internalización reforzada por el sistema educativo y los mass-media. De otra parte, probabilidades diferenciadas de acceso a los medios institucionalizados necesarios para alcanzar dichos objetivos. Nadie crea una tal situación, ni es ésta resultante querida de ninguna acción. Sin embargo, esta contradicción estructural es constantemente recreada y reforzada cuando apoyamos la ampliación del sistema educativo, de los mass-media o la desigualdad económica institucionalizada en la propiedad privada.

- Otro ejemplo, especialmente paradójico. De acuerdo con Sutherland ${ }^{72}$, la conducta delictiva se aprende, como cualquier otra conducta, a través de un proceso de asociación diferencial: relacionándose delincuentes entre sí con mayor frecuencia e intensidad que con hombres respetuosos de la ley. Por supuesto, de ser esto cierto - y todo parece apuntar afirmativamente- las prisiones y penales serían centros de asociación diferencial y, por lo tanto, lugares de aprendizaje y socialización delictiva. Y esto es lo que son. Sin embargo, el objetivo manifiesto de prisiones, penales y centros de reclusión es exactamente el contrario: rehabilitar y resocializar al delincuente. Aquí el efecto no querido es exactamente el contrario del querido.

- Pondré un último ejemplo, especialmente llamativo, y que hoy es especialmente importante. La presión de la policía, de los políticos y el sentimiento de indignación moral de la clase media, condujeron a muchas legislaturas de países occidentales a reprimir severamente el tráfico y consumo de drogas y estupefacientes. Esta represión originó un mercado ilegal de drogas para cubrir la demanda ilegal. Los superbeneficios que se obtienen en dicho mercado negro animan y motivan a una multitud de empresarios que esperan enriquecerse rápidamente. Sin embargo, los pactos, acuerdos y transacciones de dicho mercado no pueden ser alegados ante tribunales ordinarios, de modo que un acuerdo incumplido sólo puede ser impuesto por la propia fuerza. En resumen, se genera delincuencia organizada y violenta, mafias de uno y otro tipo, que acaban imponiéndose y monopolizando el mercado. Cuanto mayor es la fuerza de la mafia, más altos son los precios a que pueden cobrar la mercancía y más aumenta el volumen de delincuencia secundaria que los adictos producen para pagar la droga. Y, por supuesto, ello confirma las especulaciones de la policía en el sentido de que hace falta más policía para controlar ese mundo. Y cuanta más policía se crea, mayores son los precios de la mercancía y mayor el volumen de delincuencia que se genera. En definitiva, al nivel de la acción consciente, policía y delincuentes se enfrentan, como es su deber. Pero al nivel del sustrato inconsciente y oculto, la situación es la inversa: policía y delincuentes mantienen una relación simbiótica de modo que aquélla obtiene mayores recursos y éstos un mercado controlado por la propia policía. Es decir, hay una variable oculta y media-

12 E. H. Sutherland y D. R. Cressey, Criminology (Lippincoty, Philadelphia, 1870). 
dora, el mercado negro, que relaciona a unos y otros, variable que es consecuencia no querida de la lucha contra la droga.

He querido utilizar ejemplos concretos y definidos para aclarar el tema. Sin embargo, los casos relevantes podrían multiplicarse. Pensemos en instituciones tan relevantes de las sociedades occidentales como las siguientes: el Estado, el mercado, las clases sociales, los sistemas de comunicación, los sistemas de ciudades, etc. Todos ellos y muchos más son resultantes acumuladas de multitud de acciones aparentemente independientes, pero que fueron generando inconscientemente una situación objetiva. Situación que, una vez creada, se impone por sí misma, fácticamente, a los actores.

He argumentado que hay hechos sociales como consecuencia de dos tipos de fenómenos: 1) que toda acción produce consecuencias no conocidas por (y, quizá, irrelevantes para) el actor, pero que pueden ser conocidas y relevantes para un observador de la situación; en todo caso, tanto la acción como la consecuencia es parte de la situación; 2) que, del mismo modo que las acciones sociales se encadenan, también se entrelazan las resultantes. Por ello. una situación está formada por una trama superficial y visible de acciones entrelazadas y por la más profunda trama de consecuencias entrelazadas. Pero hay aún un tercer argumento: que la resultante conjunta, agregada, de una serie de acciones, puede ser algo cualitativamente diferente de las mismas acciones.

El modo de analizar estos casos es, típicamente, el estudio del paralelogramo de fuerzas. Como señalaba G. Bernard Shaw en Pigmalion, «el uno quiere ir en dirección Norte y el otro en dirección Sur, y el resultado es que ambos tienen que ir en dirección Este. Aunque ambos aborrezcan el viento de Levante». Si un actor empuja hacia el Este con fuerza 4, y otro hacia el Norte con fuerza 6, el objeto se moverá en la dirección Noroeste con fuerza 5. Como decía Bertrand Russell, "los componentes no son parte de la resultante», puesto que «los efectos atribuibles a $\mathrm{A}$ y a $\mathrm{B}$ no se producen y un tercer efecto, diferente de ambos, acaece». Es decir, «lo que ocurre es que el efecto es producido por A y $\mathrm{B}$ conjuntamente, como un todo" $\mathrm{y}$, en consecuencia, «el todo no tiene más efecto que el que resulta de las partes, pero los efectos de las partes son inexistentes». Analicemos la metáfora, antes de traducirla, si es que es posible, a la ciencia social.

Nagel ha criticado el argumento de Russell; la resultante es función de un conjunto de fuerzas, de modo que si se especifica esta función «es posible deducir de tales presupuestos un conjunto de afirmaciones sobre algún complejo estructural de tales elementos» ${ }^{73}$. Sin embargo, todo lo que podremos deducir es lo que ya está contenido en la función. Si conocemos la función

${ }^{73}$ E. Nagel, «On the Statement "The Whole" is More than the Sum of its Parts», en P. F. Lazarsfeld y M. Rosenberg, The Language of Social Research (The Free Press, Glencoe, 1962), pp. 523-524. 
que aúna a $\mathrm{A}, \mathrm{B}$ y el objeto, podremos deducir la resultante, pero la función es algo que reside fuera de los actores, en la relación que mantienen entre ellos y el objeto. Por ello, tiene razón Russell al afirmar que la resultante es cualitativamente distinta de las causas que la producen, pues depende de ellas $y$ de la relación en que se encuentran. Toda la fuerza de la resultante deriva de los dos actores, pero tanto la dirección de la resultante como su propia fuerza, depende de la relación que mantienen.

¿Puede traducirse el análisis mecánico al social? Sin duda son numerosos los fenómenos sociales cuya estructura es similar a la del paralelogramo de fuerzas. El precio de una mercancía depende de la fuerza y relación que mantienen compradores entre sí, vendedores entre sí, y compradores y vendedores. La resultante -el precio-_ es cualitativamente distinta de cada una de las partes componentes. El éxito o fracaso de una reunión social (fiesta, boda, cumpleaños, etc.) depende de las personas invitadas, pero también de las acciones y reacciones que se generan entre ellas a lo largo de la ceremonia. La opinión pública es el resultado de la fuerza y dirección que imprimen a ciertos temas los mass-media, pero también del rol mediador de los líderes de opinión, etc. En todos estos casos, la resultante es un hecho social que posee los atributos de exterioridad y coactividad, pero una resultante que nadie (sino todos conjuntamente) produce.

\section{LA ACCION SOCIAL EN WEBER: UNA REDEFINICION}

Todo lo dicho anteriormente apunta hacia una redefinición del objeto de la sociología en orden a la constitución científica del hecho social. Parece que hemos abandonado totalmente la vieja conceptuación de la sociología como ciencia de la acción social, e incluso podría pensarse que hemos simplificado, y quizá caricaturizado, las diversas teorías de la acción social. Es evidente que Max Weber jamás desdeñó la relevancia científica de los factores anteriormente señalados, i.e. del hecho social en sus diversas formas.

«La sociología — dice Weber- en modo alguno tiene que ver solamente con la acción social; sin embargo, ésta constituye (para la clase de sociología aquí desarrollada) el dato central, aquel que para ella, por así decirlo, es constitutivo» ${ }^{74}$.

$\mathrm{Y}$ es igualmente cierto que si algún paradigma sociológico ha enfatizado el carácter innovador de toda interacción social, ése es el interaccionismo simbólico. Mi objetivo es diferente, y está claramente expresado en la última frase de la cita de Weber: que la acción social no puede ser constitutiva de

${ }^{74}$ M. WEBER, Economia y Sociedad, op. cit., p. 20. 
la sociología, mientras que el reconocido hecho de que las situaciones 'son cualitativamente distintas de las definiciones de la situación es el fundamento ontológico ( $\mathrm{y}$, por lo tanto, epistemológico) de la sociología.

¿Qué ocurriría si consideramos, con Weber, la acción social como el tema central de la sociología? Según Weber, una acción es social si satisface los dos requisitos siguientes: 1) que el actor otorgue a la acción un sentido subjetivo; 2) que, en virtud del sentido subjetivo que le otorga, tome en cuenta la conducta de otros y es así orientado por ella ${ }^{75}$. Ello supone excluir como temas centrales de la sociología los siguientes:

1. La situación tal y como es en sí, o, al menos, tal y como puede ser para un observador informado y con un conocimiento más amplio de la situación.

2. La acción babilual, pues ésta carece de sentido subjetivo para el actor. Es cierto que Weber incluye la acción habitual en su tipología de acciones como una forma de acción «tradicional». Pero también hace explícitas sus dudas, que comparto, sobre lo adecuado de esa subsunción:

«La acción estrictamente tradicional - en igual forma que la limitación puramente reactiva - está por completo en la frontera, y más allá muchas veces, de lo que puede llamarse en pleno una acción con sentido. Pues a menudo no es más que una oscura reacción a estímulos habituales, que se desliza en la dirección de una actitud arraigada. La masa de todas las acciones cotidianas, habituales, se aproxima a este tipo, el cual se incluye en la sistemática, no sólo en cuanto caso límite, sino porque la vinculación a lo acostumbrado puede mantenerse consciente en diversos grados y sentidos, en cuyo caso se aproxima este tipo al del número 2 (acción racional con arreglo a valores, E.L.E.) ${ }^{76}$.

Así, pues, la acción estrictamente habitual estaría más allá de la acción social y no sería tema para la sociología; si Weber la incluye, ello sólo muestra las dudas que tenía al respecto, así como que su teoría no es una teoría radical de la acción con sentido.

3. Finalmente, puesto que el criterio se sitúa en el sentido subjetivo enlazado a la acción, también quedarían excluidas las acciones orientadas causalmente bacia otros.

Weber es tajante en este punto:

«El simple hecho, sin embargo, de que alguien acepte para sí una actitud determinada, aprendida en otros que parece conveniente para

M. WEBER, op. cit., pp. 19-20.

${ }^{76}$ Ibidem, p. 20. 
sus fines, no es una acción social en nuestro sentido. Pues, en este caso, no orientó su acción por la acción de otros, sino que por la observación se dio cuenta de ciertas probabilidades objetivas, dirigiendo por ellas sus conductas. Su acción, por tanto, fue determinada causalmente por la de otros, pero no por el sentido en aquélla contenido» ${ }^{77}$.

Por ello, lo que antes llamábamos (con Turner) «sistemas de hábitos entrelazados» que encadenan las acciones (con sentido) de un actor a la mera repetición externa de la o las acciones de otro, pero al margen del sentido que estos últimos puedan otorgar a su conducta, quedarían también excluidas por ser acciones orientadas causalmente hacia otro, y no por el sentido.

Así, pues, una teoría consecuente de la acción social excluye no sólo la situación en sí misma, sino también todo un conjunto de acciones que pueden ser muy relevantes en numerosos contextos. El propio Weber afirmaba repetidamente que la masa normal de las acciones cotidianas son rutinarias y habituales, $y$ podemos añadir que son también - y consecuentemente- numerosas las acciones orientadas causalmente hacia otro u otros. Esto implica que, si la sociología quiere seguir utilizando la acción como punto de referencia, es necesario redefinirla. La redefinición que propongo, que incluiría al menos los dos tipos de acción que Weber excluyó, se basa en el criterio del entrelazamiento objetivo de las acciones y no en el criterio del sentido. Es decir, se considera aquí como acción social toda aquella acción, con o sin sentido subjetivo, que objetivamente, esto es, desde el punto de vista de un observador con un conocimiento más amplio de la situación, toma en cuenta la acción de otro $u$ otros. Tal definición abarca, por supuesto, la acción con sentido, pues está encadenada objetivamente (aunque a través del sentido) a la de otro, pero también toda aquella acción que, careciendo de sentido desde el punto de vista del actor es, sin embargo, social en la medida en que se halla integrada en cualquier sistema encadenado de acciones.

Qué duda cabe que en numerosas ocasiones el cemento que aglutina la vida social es el sentido subjetivo que los actores otorgan a sus acciones o las de otros; pero éste no es el único elemento aglutinador y, con toda probabilidad, no es el más eficaz. Por ello, si queremos hacer de la sociedad el centro de la sociología, hay que remachar que se halla trabada por numerosos lazos que son desconocidos por los actores, pero no por ello dejan de ser reales. Es más, si la sociología es necesaria en absoluto, ello se debe a que las acciones de los sujetos asumen y dan por supuesto en qué medida su conducta está socialmente pautada y, especialmente, en qué medida depende de otras acciones correlativas. Los actores desconocen estos encadenamientos, y por ello frecuentemente frustran sus objetivos; es misión de la sociología restablecer la transparencia colectiva llevando a conciencia el hecho social en cuanto sustrato inconsciente de la situación.

${ }^{n}$ Ibidem, p. 19. 


\section{LA SITUACION, OBJETO CONSTITUTIVO DE LA SOCIOLOGIA}

Pero incluso así redefinida, es insatisfactorio afirmar que el objeto de la sociología es el estudio de la acción social. Y ello porque el énfasis en la acción, aun cuando sea como acción entrelazada y, por lo tanto, como hecho social, tiene que completarse con el estudio inverso: cómo las acciones derivan de situaciones, en qué medida son determinadas socialmente, cómo son aprendidas y pautadas para ajustarse a coacciones estructurales. De hecho, hasta el momento - y siguiendo el procedimiento de Watkins- nuestro modelo ha sido el del individualismo metodológico: comenzamos con la acción y avanzamos desde ella hacia las consecuencias y sus entrelazamientos para elaborar los hechos sociales. Este es, por muy objetivista que trate de presentarse, un modelo liberal y nominalista. Sin embargo, hay que otorgarle justificación a Marx, cuando afirmaba - contra Locke o Smith - que los intereses y deseos están ya socialmente determinados y pautados; es decir, si la acción genera hecho social como parte de la situación, también la situación genera acciones pautadas y objetivas, lo que usualmente se denomina acciones típicas. En definitiva, tampoco la acción es una respuesta azarosa, y del mismo modo que su análisis no debe interrumpirse allí donde el actor se para, sino que debe continuar con el estudio de las consecuencias, tampoco los elementos previos a la acción, es decir, las motivaciones (por qué o para qué) o los intereses son trascendentes a la sociología y pueden y deben ser analizados.

¿Qué ocurriría si estudiáramos sólo las consecuencias, pero no los presupuestos de la acción? En tal caso las acciones, cada una respondiendo a sus motivos, serían teóricamente azarosas, de modo que igualmente serían azarosas las consecuencias y los hechos sociales. Esto carece de sentido empíricamente. La sociedad está traspasada de regularidades y repeticiones típicas, tanto conscientes como inconscientes, y si esto es así, ello se debe a que también las acciones son generadas típicamente, pues responden a situaciones igualmente típicas. Desde la perspectiva del hecho social hay que concebir la acción como generada por situaciones repetitivas, de modo que la acción lo es también y produce consecuencias y hechos sociales igualmente típicos. Por ello, el objetivo de la sociología es el hecho social, pero como factor constituyente y constituido de la acción social o, si se prefiere, de la acción social como factor constituido y constituyente del hecho social.

El «neoidealismo» o subjetivismo ${ }^{78}$ de la sociología interpretativa no se caracteriza (como el idealismo filosófico) por la negación de la objetividad como tal, sino sólo porque no la alcanza nunca, ni ontológica ni epistemo-

${ }^{78}$ Los calificativos no son míos; véanse J. Rex, Discovering Sociology (Routledge and Kegan Paul, Londres, 1973), p. 212; MENNELL, «Ethnomethodology and the New "Methodensreit"», Acta Sociológica, 18, 4 (1975); R. K. MERTON, Sociological Ambivalence, op. cit., p. 174. 
lógicamente; porque nunca llega a fundar la realidad del hecho social, que no es identificable ni con el hecho natural o físico, ni con el hecho psíquico o de conciencia.

En esto, como en muchos otros aspectos, la sociología interpretativa se muestra más próxima al Parsons de La estructura de la acción social y a la sociología normativa que a las orientaciones básicas de la sociología europea; recordemos que esta primera gran obra de Parsons fue criticada por Merton precisamente porque tomaba en consideración sólo el punto de vista del actor. $\mathrm{Y}$ así, es posible decir que si lo que constituye la sociología como ciencia autónoma es la existencia de los hechos sociales, el idealismo sociológico no es una sociología, sino la disolución de la misma a través de la disolución de su objeto; una sociología sin sociedad ${ }^{79}$. Ello puede corresponder a la orientación fenomenológica subyacente: «el fenomenólogo - dice Schutzno tiene que vérselas con los objetos mismos; está interesado en su sentido en cuanto constituido por las actividades de nuestro espíritu» ${ }^{80}$. Pero como decía Hamlet a Horacio, hay más cosas en el cielo y en la tierra de las que contiene tu filosofía y el espíritu nunca abarca la totalidad de lo real. La situación no es nunca idéntica con la definición de la situación, y ello no porque el actor sea más o menos ignorante o lúcido, sino porque ninguna acción produce exactamente lo que se quiere. Si, por el contrario, identificamos la situación con su definición subjetiva, entonces, como dijo Lichtman, «la profecía que se autocumple deviene el paradigma de la acción social» ${ }^{81}$, el punto de vista del observador es innecesario y la sociología es inútil. El famoso dictum de Thomas «si los hombres definen las situaciones como reales, éstas son reales en sus consecuencias» ${ }^{82}$ tiene que armonizarse con la réplica de Merton: «Si los hombres no definen como reales las situaciones que lo son, éstas son, sin embargo, reales en sus consecuencias» ${ }^{83}$.

Por el contrario, una concepción sociológica de la realidad social entiende ésta como resultante, consciente o no, de la acción, de modo que la definición de la situación no puede nunca identificarse con la situación. Esta es siempre algo más y algo menos que aquéllas. Es algo más porque los actores perciben las situaciones selectivamente y porque las consecuencias de sus acciones forman parte de la situación objetiva; y es algo menos porque sólo los actores otorgan sentido a la situación y sin ese sentido, trascendente a la situación misma, ésta no llega a constituirse. Por ello, la definición de la situación es

${ }^{79}$ Esta es, literalmente, la conclusión de W. W. MaYrL en relación con la etnometodología: "Ethnomethodology: Sociology Without Society", Catalyst, 7 (1973), 15 y ss.

${ }^{80}$ Citado por W. W. MaYrL, op. cit., p. 17.

81 R. Lichtman, «Social Reality and Consciousness», en J. D. Colfax y J. L. Ronch (eds.), Radical Sociology (Basic Books Inc., Nueva York, 1971), pp. 149 y ss.

${ }^{82}$ Que no es propiamente de él solo, sino de Thomas y D. SWaIne, en The Cbild in America (Knopf, Nueva York, 1928), p. 572.

${ }^{83}$ R. K. Merton, Sociological Ambivalence, op. cit., p. 177. 
parte de la situación, y parte constitutiva, pero no la agota. Y por ello, la situación es sólo parcialmente subsumida en la definición de la situación.

El juego, drama o teatro social se genera en una espiral entre situaciones y acciones en el que hay un doble emergente: porque la situación objetiva es siempre algo más (o algo menos), en todo caso diferente de lo que quieren los actores, y porque la acción está sólo parcialmente determinada por la situación, y su esclarecimiento total exige tomar en cuenta lo que el propio actor aporta en términos de percepción, conocimiento, motivos, etc., incluyendo la propia definición de la situación. Así, si imaginamos una interacción entre un conjunto de actores, la relación puede representarse como una espiral:
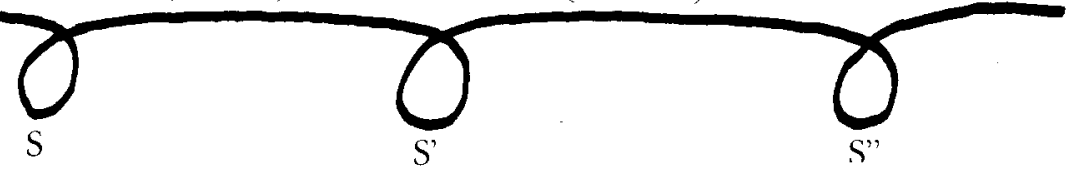

Las acciones generan nuevas e inesperadas situaciones que, a su vez, estimulan nuevas acciones que alteran la situación, etc. Por ello, la relación entre hechos (sociales) y actores es una relación dialéctica y los hombres se generan a sí mismos, produciendo un mundo en parte extraño y ajeno, que más tarde recobran y recuperan en sus acciones:

«Por una parte, los hechos sociales están objetivamente dados; los actores entran en su constelación que los determina... Por otra parte, el actor reacciona hacia la situación que le determina: la valora, piensa sobre ella, la acepta o la rechaza, construye sobre ella ideales u objetivos» ${ }^{84}$.

$\mathrm{Y}$ precisamente porque acciones y situaciones nunca coinciden, la historicidad es un dato radical de la vida social. Pues el actor es sobrepasado por una situación que es sobrepasada por el actor y nadie nada dos veces en el mismo río. Si las cosas no ocurrieran de este modo, la vida social sería una repetición constante de sí misma, representación de juegos sociales ya conocidos; sólo entonces la metáfora dramatúrgica sería una afirmación ontológica. Mientras tanto, la ambivalencia constituyente-constituido se mantiene en el doble sentido que, en casi todos los idiomas occidentales, tienen los términos «sujeto" y «actor». Sujeto, como punto de referencia de la acción, pero también como punto de imputación, es decir, como ser construido. Actor, como creador y generador, pero también como representante de un papel social al que da vida, pero que le limita.

84 R. Rezsohazy, Theorie et critique des faits sociaux, op. cit., p. 36. 


\section{SOCIOLOGIA Y PSICOLOGIA (DESDE EL PUNTO DE VISTA DEL OBJETO)}

Esto nos permite abordar el tema de las relaciones entre sociología y psicología. Si suponemos, como Mandelbaum, que disponemos de un lenguaje sociológico S, con términos como «tol», «institución», «estructura social», «clase social», etc., y de un lenguaje psicológico $\mathrm{P}$, con términos como «actitud», «motivación», «norma», etc., es sin duda cierto que

«si tratamos de analizar los hechos sociales por medio de los pensamientos que guían la conducta de los individuos, algunos de los pensamientos tendrán referencias sociales $\mathrm{y}$, por lo tanto, los conceptos sociológicos no serán expurgados de nuestros análisis» ${ }^{85}$.

Los bechos sociales, al menos algunos, son tomados en cuenta por los actores, de modo que nuestro imaginario lenguaje psicológico $P$ nos remitirá al lenguaje sociológico $S$. Por poner un ejemplo, el análisis dramatúrgico de Goffman en La presentación de sí mismo en la vida cotidiana, al mostrar cómo los actores manipulan los roles que representan para conseguir presentaciones de sí mismos favorables y gratificadoras, está indicando que el concepto de «rol» no es (al menos únicamente) un útil ideal-típico construido por el sociólogo para describir la vida social, sino también parte de las nociones del sentido común que los sujetos emplean en sus estrategias cotidianas para vérselas con el mundo. Es decir, la categoría del rol forma parte no sólo del arsenal del sociólogo, sino también del de los actores; es, pues, parte de la etnosociología ${ }^{86}$. Esto no es nada sustancialmente nuevo; era un punto central en la metodología weberiana y es el instrumento analítico clave en la reconstrucción de la sociología comprensiva de Schutz. Como decía Weber:

«La interpretación de la acción debe tomar nota del importante hecho de que aquellos conceptos empleados, tanto por el lenguaje cotidiano como por el de los juristas (y también por el de otros profesionales), son representaciones de que algo, en parte, existe y, en parte, se presenta como un deber ser en la mente de hombres concretos, la acción de los cuales orientan realmente; y también debe tomar nota de que esas representaciones, en cuanto tales, poseen una poderosa y a menudo dominante significación causal en el desarrollo de la conducta humana concreta... (un Estado moderno - como complejo de una específica actuación humana común - subsiste en parte muy considerable de esta forma:

${ }^{85}$ M. Mandelbaum, «Societal Facts», op. cit., p. 109.

${ }^{86}$ E. Goffman, The Presentation of Self in Everyday Nife (Doubleday, Nueva York, 1959; hay traducción en Amorrortu). En el mismo sentido, véase R. H. TURNER, "The Role and the Person», American Journal of Sociology, 84 (1978), 1 
porque determinados hombres orientan su actuación por la representación de que aquél debe existir o existir de tal o cual forma)...» ${ }^{87}$.

Así, pues, la idea de Estado forma parte de las representaciones psíquicas de sentido común tanto como de las del politólogo o jurista, y otro tanto puede decirse de numerosos conceptos de la economía o de la sociología.

Ahora bien, si sólo dispusiéramos de este argumento no podríamos afirmar que ula traducción de los conceptos de $\mathrm{S}$ en $\mathrm{P}$ no sería completa si tal traducción tuviera que emplear conceptos de $S_{\gg}{ }^{88}$. El problema radica en que el lenguaje $S$ contiene -o al menos debería contener-conceptos que no aparecen en el lenguaje $P$ (al menos en el lenguaje $P$ de los no-sociólogos), puesto que serán conceptos cuyo referente es desconocido para el individuo común. Así, cuando hablamos de la gramática de un lenguaje, de las funciones latentes de una institución, de los sistemas de parentesco o de las tasas de suicidios o de homicidios nos referimos a fenómenos de este tipo existentes en el lenguaje $\mathrm{S}$, pero no en el $\mathrm{P}$. Por ello, la relación entre ambos lenguajes vendría representada por dos círculos tangentes, como muestra la figura.

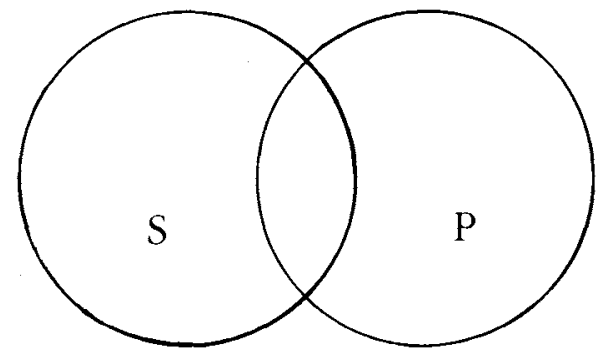

$Y$ podemos concluir que la traducción del lenguaje $S$ al $P$ dejará muchos residuos y será incompleta. Una sociología que se limite a penetrar en la conciencia de los sujetos descubrirá una parte muy restringida de la realidad social, pues ésta es, en gran medida, inconsciente o ignorada por los actores. Este y no otro es el argumento de Popper para fundar la independencia de la sociología:

«Lo que podemos en principio explicar psicológicamente, y lo que debemos presuponer en toda explicación psicológica es el ambiente social del hombre. La tarea de describir este medio ambiente social... es la tarea fundamental de la ciencia social. Parece apropiado asignar esta tarea a la sociología» ${ }^{89}$.

${ }^{87}$ M. Weber, Economía y Sociedad, op. cit., p. 13.

${ }^{88}$ Mandelbaum, «Societal Facts», op. cit., p. 111.

${ }^{89}$ K. Popper, «The Logic of the Social Sciences», op. cit., p. 102. Dada la semejanza entre las ideas popperianas sobre las consecuencias no queridas de la acción y la teoría marxista de la cosificación, así como su énfasis en la sociología como ciencia de la realidad 
Es la situación, lo que Popper llama medio ambiente social, lo que genera la sociología, y no la acción. Nuestro individualismo es metodológico $-\mathrm{y}$ con matices-, pero de ningún modo ontológico.

\section{TRABAJO MUERTO Y TRABAJO VIVO}

Comenzamos afirmando que la sociología no podía ser una ciencia de la acción y mostramos cómo el estudio de las consecuencias de la acción debía también ser parte de sus preocupaciones. Ahora bien, por mucho que las consecuencias de la acción puedan considerarse el dato fáctico elemental y constitutivo de la sociología, y por mucho que el estudio de la acción deba ampliarse, sería también insuficiente limitar la sociología al estudio de las consecuencias de la acción. Y ello no sólo porque, como decía anteriormente, también los motivos, socialmente determinados por situaciones previas, y en última instancia, la personalidad del actor o su estructura de carácter, objetivación de una biografía personal de situaciones y estímulos, debe ser abarcado por la sociología, sino por otras tres razones.

Primero, porque es evidente que no todas las consecuencias no intencionadas de la acción pertenecen al campo de la sociología, y ni siquiera al de las ciencias sociales; así, la contaminación producida por nuevos productos químicos o las epidemias derivadas de los nuevos sistemas de transporte, etc., son temas ajenos a la sociología. Temas que, sin duda, forman parte de la situación fáctica y que, por tanto, deben ser tomados en cuenta como dato por un observador social con un conocimiento amplio de la situación, pero que quedan fuera de su área de intereses. Los elementos relevantes de la situación para el sociólogo son los sociales, no todos, so pena de que la sociología pase a ser una enciclopedia del universo.

Además, hay muchos fenómenos que interesan al sociólogo y que son resultados intencionados de la acción. Así, cabe estudiar la política de un gobierno concreto y analizarla como resultado querido y deseado de los actores políticos que causan lo que se quería y que interesa precisamente por ello. El cambio de énfasis desde la acción a sus consecuencias no supone eliminar las consecuencias queridas, sino sólo ampliar el estudio a las no queridas, pues son éstas, y no las primeras, las que justifican el punto de vista del observador y, por ello, legitiman al sociólogo como experto que posee (o debe poseer) un conocimiento más vasto del fenómeno.

Por último, hay que subrayar el hecho, a menudo olvidado, de que, puesto que los sociólogos están interesados en la realidad social, están igual-

social objetiva, cabe preguntarse si el aparente acuerdo entre Popper y Adorno en la famosa «disputa» sobre el positivismo se debió al mutuo recelo - como parece sospechar Dahrendorf_- o a un acuerdo de fondo que la diferencia de lenguajes no hacía sino encubrir. 
mente interesados en aquellos factores o elementos que, aunque analíticamente diferentes de la realidad social como conjunto de interacciones, son consecuencias de interacciones pasadas, ayudan a explicar o comprender situaciones y son, por ello, parte de la realidad objetiva de la relación.

«Para comenzar — decía Durkheim—, no es cierto que la sociedad está compuesta sólo de individuos; incluye también objetos materiales que juegan un papel esencial en la vida común. El becho social se materializa a veces basta el punto de devenir un elemento del mundo exterior; por ejemplo, un tipo concreto de arquitectura es un fenómeno social, pero está parcialmente incorporado en casas y edificios de muchas clases que, una vez construidos, devienen realidades autónomas, independientes de los individuos. Lo mismo ocurre con las líneas de comunicaciones y transporte, útiles y máquinas empleados en la industria o en la vida privada... el lenguaje escrito, etc. La vida social, que por así decirlo, se ha cristalizado y fijado en soportes materiales, se encuentra así, por ello, exteriorizada y es, desde el exterior, que actúa sobre nosotros...

El mismo comentario puede aplicarse a esas fórmulas definidas donde se condensan, bien los dogmas de fe, bien las reglas jurídicas cuando son exteriormente fijadas bajo una forma consagrada»"

La estructura de una ciudad o de un sistema de ciudades, la red de comunicaciones o de transporte, o la distribución de un cuarto de estar ( $\mathrm{S}$. Chapin) interesan por variados motivos: porque son cristalización de situaciones pasadas, porque dicen algo o informan sobre el actor o la situación, y porque, además, actúan como controles estructurales de la acción. El mundo físico, tal y como lo conocemos, es en una gigantesca medida el resultado del trabajo acumulado de muchas generaciones; es, pues, resultante (querida o no) de acciones acumuladas. Pero es, además, por su propia facticidad material, el hecho social por antonomasia, la sociedad y su historia objetivada y materializada en edificios, calles, fábricas, caminos, etc. Y todo ello canaliza y, por lo tanto, controla y limita la acción.

En tal sentido, si a la sociología le interesa, ante todo, el entrelazamiento de acciones que constituye la totalidad social, le interesa igualmente lo que a través de ese entrelazamiento se genera: la sociedad como sistema de sujetos en interacción entre sí y el mundo, objetivándose y reproduciéndose en una realidad labrada día a día, que es, por así decirlo, el espejo materializado de la sociedad o, mejor aún, su negativo. En este sentido, un edificio de oficinas es el sustento, base y negativo de una burocracia, y puede medirse la jerarquía de los ocupantes por el volumen de sus despachos. $\mathrm{Y}$ un tresillo es sustento

${ }^{90}$ E. Durkheim, Les règles de la méthode sociologique, op. cit., pp. 354-355. 
base y negativo de una charla, pero no sirve para una reunión de trabajo. Esto es evidente, pero lo evidente se escapa muchas veces, especialmente al sentido común. El trabajo muerto es generado por el trabajo vivo, pero es también su sustento y el primer sistema de control social. $Y$ por ello podemos intentar conocer una sociedad desaparecida a través de sus utensilios, casas y objetos materiales, como proceden los arqueólogos y paleoantropólogos. Cometeremos errores, pues el sentido subjetivo de la acción se ha desvanecido junto con la vida que animaba esos objetos, pero ello no impide alcanzar un nivel relevante de conocimiento externo y, a través de él, por inferencia, alguna penetración en su cultura.

Pero una sociedad no sólo se objetiva físicamente. Si la ciudad o un sistema de ciudades ofrece uno de los ejemplos más claros de hecho social en el sentido de acumulación de consecuencias de líneas de acción, otro tanto puede decirse de otros fenómenos no materiales. Así, en primer lugar, la lengua:

«La masa misma —escribe Saussure- no puede ejercer su soberanía sobre una sola palabra; la masa está atada a la lengua tal cual es... $\mathrm{Si}$ se quiere demostrar que la ley admitida en una colectividad es una cosa que se sufre, y no una regla libremente consentida, la lengua es la que ofrece la prueba más concluyente de ello» ${ }^{91}$.

Y por ello, escribe Ponzio, utilizando nuestro mismo lenguaje:

«Las características que Saussure atribuye al hecho social, por las que individualiza la lengua como el lado social del lenguaje, son las mismas que lo social adopta en el sistema capitalista, presentándose como resultado no querido de las acciones de cada uno, como regido por leyes imprevistas e independientes de los fines que cada uno se propone, como resultante de acciones individuales que domina a los individuos como potencia extraña. En este sentido, para Saussure, la lengua es un becho social: ejerce sobre el individuo una constricción externa; no es función del sujeto hablante, sino resultado pasivo de la práctica de la parole, producto sufrido, situado fuera de la voluntad de los individuos $» 92$.

No sólo la lengua, sino todos aquellos fenómenos sociales que se construyen sobre ella: las concepciones del mundo, mitos, religiones, ideologías, etcétera, son también resultante de una acumulación cultural de símbolos y sistemas simbólicos que cada generación produce, en parte queriendo y, en

${ }^{91}$ F. DE SAussure, Curso de Lingǘstica General (Losada, Buenos Aires, 1945), p. 135. p. 188.

${ }_{2}$ A. Ponzio, Producción lingüística e ideologia social (A. Corazón, Madrid, 1974), 
parte también, sin quererlo, pero que están ahí, dentro de cada actor pero fuera de su control, determinando los temas y problemas de su pensamiento, canalizando sus especulaciones, definiendo su universo potencial de discurso. Universo que es también el negativo de la vida social, pues hablar es comunicar y se comunica sobre lo que existe una vez captado simbólicamente. Pero también sobre todo aquello que puede crearse en base a los símbolos y sus múltiples combinaciones, pues el hombre construye primero en su mente lo que más tarde realizará con sus manos. Y así, del mismo modo que la acción es un emergente en la situación, cada generación supera, gracias al acervo simbólico-cultural que maneja, el trabajo muerto de generaciones anteriores y construye parcialmente su propio mundo, mundo que siempre será algo más de lo que ellos querían. Pues los hombres hacen la historia, pero no saben a ciencia cierta lo que hacen.

Esta discusión nos ha llevado a las puertas de un tema central y que sólo podemos esbozar: el de la estructura social, que es aquí concebida como la interrelación dinámica de tres tipos de fenómenos sociales, sólo analíticamente diferenciables: la sociedad, propiamente dicha, como sistema de sujetos de interacción, parte activa y dinámica de la estructura social; el universo material, que sustenta y media dichas relaciones sociales, que es, sobre todo, trabajo objetivado de generaciones anteriores $y$, en parte, producto (querido o no) de los vivos; y el universo simbólico, que es igualmente, en parte, trabajo muerto de generaciones pasadas $y$, en parte, producto (querido o no) de los vivos. Entre estos tres niveles, la sociedad, el universo simbólico y el universo material, hay evidentes interrelaciones, aunque los tres se caracterizan por su facticidad: la que representa el otro como censor de mi conducta, un otro que espera de mí cierto comportamiento y que me sanciona o retira su afecto si no cumplo lo esperado; la que representa la naturaleza humanizada, que físicamente se impone con su misma presencia; y, por último, la imposición de un sistema simbólico y de pensamiento que controla y limita la capacidad de comprender y de pensar, pues si los límites del lenguaje no son los límites de mi mundo, sí que son el límite del pensamiento y la comunicación.

Recogiendo el tema central de estas páginas, llegamos a la conclusión siguiente: la sociología se ha de ocupar de la acción social -en el sentido redefinido anteriormente-, de las consecuencias queridas o no de la acción, $\mathrm{y}$ de las situaciones como resultantes de dichas consecuencias. Cuatro elementos, pues, analíticamente diferenciables, pero entrelazados empíricamente. De este modo, el concepto de hecho social se expande para abarcar, además de las relaciones sociales entrelazadas, los diferentes modos en que pasadas acciones han quedado objetivadas $\mathrm{y}$, como tal, son exteriores y coactivas a los actores. Es más, desde la perspectiva del hecho social, éstos son los elementos más estables de la vida social, puesto que, por su mera existencia, canalizan tanto la conducta externa como el pensamiento. Mientras que los individuos son —como ya decía Durkheim - la parte vital y animada de la sociedad, 
estas objetivaciones constituyen el elemento más claramente fáctico, productos sociales que tienen sólo una vida colectiva, que son, por lo tanto, autónomos a cada individuo y que constituyen el cuerpo y el alma, respectivamente, de la colectividad y de la sociedad como agregado.

Por ello, cuando aludimos a la facticidad social, podemos estar refiriéndonos, al menos, a cuatro tipos distintos:

1. Desde el punto de vista inmediato del actor, la facticidad social alude al otro como censor espontáneo de mi conducta, o bien a ese mismo control, una vez interiorizado por el actor. En este sentido, es sólo el control situacional ejercido por los seres humanos sobre los otros.

2. Sin embargo, y desde el punto de vista del observador, la facticidad social abarcaría otros tres elementos:

a) La situación, tal y como ha llegado a ser, y en la medida en que es un resultado no querido. En tales condiciones, la situación reposa sobre sí misma y se impone sobre los actores.

b) Las cosas objetivadas y materializadas como encarnaciones y sustratos de relaciones sociales: edificios, ciudades, caminos, instrumentos, objetos, etc. Todos ellos son, individual y colectivamente, soportes y mediaciones de relaciones sociales específicas, de tal modo que nuevas relaciones sociales requerirían cambiar ese mundo fáctico, la sociedad materializada. Aquí el control social es, literalmente, objetivo.

c) Finalmente, las objetivaciones que se presentan como conceptos, sistemas de ideas o creencias, modos de pensar, etc., incorporados en el lenguaje cotidiano, pero también en libros, prácticas educativas, etc., y que son la contrapartida significativa y comunicativa del mundo subjetivo, lo que, por utilizar el lenguaje de Alfred Weber, podríamos llamar «cultura» (en contraposición a lo aludido antes, que sería la «civilización»).

\section{DESCOSIFICANDO EL HECHO SOCIAL}

Pretendo con estos comentarios evitar una tentación por la que es hoy frecuente dejarse arrastrar. Me refiero a la prematura totalización de la sociedad, lo que antes llamé, aludiendo a Lukacs y la Teoría Crítica, una cosificación de la cosificación, y que en este campo podría manifestarse como la creencia en la absoluta facticidad y opacidad de la vida social. Contra esta generalizada actitud teórica es necesario afirmar que la facticidad social es una variable continua, que puede darse en mayor o menor medida y esto en relación con cualquier sistema de acción. El continuo de Toennies GemeinschabftGesselschaft recoge, al menos parcialmente, esta variabilidad que se extendería desde aquellas sociedades (empíricamente imposibles) con un nivel nulo de 
interdependencia a aquellas otras (igualmente imposibles) con un nivel nulo de dependencia. En un extremo, el máximo de individualismo, y en el otro, un organismo colectivo.

Ahora bien, este modelo general es igualmente aplicable al entrelazamiento de acciones que al de resultantes, y tanto uno como otro pueden darse en diversa medida. Por ello, el nivel de facticidad social de un sistema de acción dependerá de dos variables. En primer lugar, de que se produzcan o no (y en qué medida) consecuencias no queridas y del grado de entrelazamiento de las mismas; pero, además del grado de objetivación de la propia sociedad, del grado en que ha conseguido materializarse, pues cuanto más cerrada sea la cáscara del trabajo muerto (sea éste «cultura» o «civilización»), mayor será el constreñimiento sobre el trabajo vivo y menores las alternativas abiertas a la acción.

Por ello, al analizar un sistema de acciones es necesario plantear tres distintas preguntas que nos servirán para indicar el nivel de facticidad o, si se prefiere, el «volumen» de material sociológico que ofrece:

1. ¿Hay resultantes? No todo sistema de acción genera el mismo volumen de consecuencias no queridas. Así, un sistema económico de productores autárquicos limita las consecuencias no queridas de la acción al mínimo, mientras que a medida que aumenta la especialización y la división del trabajo, $y$, por tanto, la interdependencia, más difícil será controlar las consecuencias últimas de la acción. Por ello, al comparar sociedades tradicionales de solidaridad mecánica con sociedades modernas de solidaridad orgánica, comprobamos que las primeras consiguen un alto grado de transparencia social a costa de un bajo nivel de cohesión, y por ello se hallan más expuestas a los avatares y las coyunturas naturales (clima, cosechas, caza, catástrofes, etc.), mientras que las segundas, con altos niveles de cohesión interna, dependen más de sí mismas que de la naturaleza, pero pagan por ello un precio de facticidad social y opacidad. En definitiva, sustituyen parcialmente la naturaleza por una segunda naturaleza social, igualmente ajena y coactiva.

2. Incluso si hay consecuencias no anticipadas puede ocurrir que éstas sean recurrentes y típicas, de tal modo que acciones típicas generadas en situaciones igualmente típicas producen resultantes recurrentes que, por lo mismo, llegarán a ser conocidas, aunque no se sepan las causas que las originan. En tales casos, la espiral que enlaza acciones y situaciones se cierra circularmente.

En la medida en que la gran mayoría de las acciones cotidianas son habituales, podemos sospechar que esta pauta cíclica debe ser bastante común. Y eilo era de esperar, puesto que la pauta de recurrencia protege a los actores contra el azar de las consecuencias no intencionadas, siempre peligrosas; no 
porque no se generan, sino porque al ser recurrentes son esperadas y previsibles.

3. Finalmente -y con ello introducimos una variable de gran importancia- sería necesario preguntarse por el nivel de reflexividad social del sistema de acción, es decir, en qué medida los actores estudian las eventuales consecuencias no intencionadas de sus acciones, pues ello puede alterar radicalmente las acciones $y$, por lo tanto, las situaciones. Así, los actores pueden ampliar su punto de vista para descubrir que fenómenos sociales hasta entonces atribuidos al azar o a leyes naturales o supratemporales son sólo resultantes de su propia conducta, lo que sin duda altera ésta en algún sentido. Aquí también la diferencia esencial entre las sociedades tradicionales y las modernas radica en que las últimas han establecido un mecanismo institucionalizado de reflexión colectiva - la sociología - que les permite una racionalización suplementaria de sus acciones. Las sociedades modernas son constantemente inspeccionadas por científicos sociales que comunican sus descubrimientos a la sociedad, que los utiliza para planificar de nuevo sus líneas de acción y reelaborar sus estrategias.

Asumiendo que algunas resultantes son relevantes para la acción y el actor que las desconoce, hay dos mecanismos para protegerse frente a ellas. Primero, un sistema que produce reglas de conducta (normas) y las implementa en toda acción de modo que conductas tipificadas generan situaciones tipificadas y éstas, a su vez, conductas tipificadas. Segundo, un sistema basado en la reflexividad del actor sobre las resultantes de la acción, para así redefinir ésta en base al feed-back informativo. Mediante la recurrencia las conductas son congeladas y cristalizan en sistemas estables y ordenados; mediante la reflexividad las conductas se alteran y cambian, superando las situaciones insatisfactorias de modo dinámico, pero ordenado y previsible. El primer mecanismo social garantiza una estabilidad ordenada; el segundo, un cambio social ordenado. La reflexividad es así un mecanismo para controlar el orden social contra los azares e incertidumbres del cambio histórico. 


\section{BIBLIOGRAFIA}

Adorno, Th. W.: Dialéctica Negativa (Taurus-Cuadernos para el Diálogo, Madrid, 1975). Agassi, J.: «Institutional Individualisn", British Journal of Sociology, 2 (1975), 144.

Althusser, L.: Montesquieu, la politique et l'bistoire (Presses Universitaires de France, París, 1959).

Aron, R.: Les étapes de la pensée sociologique (Gallimard, París, 1967).

Becker, C.: The Heavenly Ctly of the Eightentb-Century Pbilosophers (New Haven, Conn., 1932).

- Voz «Progress», en Seligman y Johnson (eds.), Encyclopedia of the Social Sciences (McMillan, Nueva York, 1934, vol. XIl), 495 y ss.

Becker, H., y Barnes, H. E.: Social Thought From Lore to Science (Dover Publishers, Nueva York, 1961).

BELL, D.: Las contradicciones culturales del capitalismo (Alianza Edit., Madrid, 1977).

Bernstein, R. J.: The restructuring of Social and Political Theory (Harcourt Brace Jovanovitch, Nueva York, 1976).

Buumer, H.: Symbolic Interactionism. Perspective and Metbod (Prentice Hall Inc., Englewood Cliffs, New Jersey, 1969).

Brown, R. H., y Layman, S. M.: Structure, Consciouness and History (Cambridge University Press, Cambridge, 1978).

BurtT, E. A.: The Metapbysical Fountation of Modern Science (Doubleday, Garden City, Nueva York, 1954).

Carveth, D. L.: «The Disembodied Dialectic: A Critique of Sociological Relativism», Theory and Society, 4, 1 (1977), 81.

García-Calvo, A.: Apotegmas sobre el marxismo (La Banda de Moebius, Madrid, 1977).

Chasin, G.: «G. H. Mead: A Social Psychologist of the Moral Society», Berkeley Journal of Sociology, IX (1964), 95.

Blumer, H.: «Comments on Mr. Chasin's Article», Berkeley Journal of Sociology, IX (1964), 118.

ChILDE, G.: Man Makes Himself (Wats, Londres, 1956; hay traducción en el FCE, México).

Colfax, J. D., y Roach, J. L. (eds.): Radical Sociology (Basic Books Inc., Nueva York, 1971).

De Saussure, F.: Curso de Lingiiistica General (Losada, Buenos Aires, 1945).

Douglas, J. D.: The Social Meaning of Suicide (Princeton University Press, Princeton, 1967).

Dreitzel, P. (ed.): Recent Sociology n." 2. Patterns of Communicative Bebavior (The MacMillan Co., Nueva York, 1970).

Durkherm, E.: De la división du travail social (Presses Universitaires de France, París, 1960).

- Les régles de la métbode sociologique (Presses Universitaires de France, París, 1968).

Elias, N.: The Civilizalion Process (Urizen Books, Nueva York, 1978).

Emmes, D., y Maclntyre, A. (eds.): Sociological Theory and Pbilosophical Analysis (The MacMillan Co., Nueva York, 1970).

Feigl, H., y Bronbeck, M. (eds.): Readings in the Pbilosopby of Science (Appleton Century Crofts, Nueva York, 1953).

Gerth, H. H., y Wright Mills, C.: From Max Weber (Oxford University Press, Nueva York, 1969).

Goffman, E.: The Presentation of Self in Everyday Nife (Doubleday, Nueva York, 1959; hay traducción en Amorrortu).

- Encounters (Bobbs Merryls Co., 1961).

- The Social Construction of Reality (Doubleday Anchor Books, Nueva York, 1966; hay traducción en Amorrortu).

Hindes, B.: Philosopby and Methodology in the Social Sciences (The Harvester Press, Sussex, 1977).

Horne, A.: The Social Thought of Bernard Mandeville (Columbia University Press, 1978).

Jarvie, I. C.: Concepts and Society (Routledge and Kegan Paul, Londres, 1972). 
Jiménez Blanco, J., y Moya, C. (eds.): Teoria sociológica contemporánea (Tecnos, Madrid, 1978).

Katz, E.: «The Two-Step Flow of Communication. An Up-to Date Report of an Hypothesis», Public Opinion Quarterly, 21 (1957), 61.

Lazarsfeld, A. P., y Rosenberg, M.: The Language of Social Research (The Free Press, Glencoe, 1962).

Lenoff, M.: The Structure of Social Science (G. Allen and Unwin, Londres, 1974).

MacNall, S. G..: The Sociological Persective (Little Brown and Co., 1971).

Mandeville, B.: The Fable of the Bees (edición a cargo de F. B. Kaye, Clandon, Oxford. 1957).

Manuel, F.: The New World of Henry Saint-Simon (University of Notre Dame, Indiana, 1963).

- The Prophets of Paris (Harvard University Press, Cambridge, 1962).

Marcuse, H.: Etica de la revolución (Taurus, Madrid, 1970).

Marx, K.: Grundrisse (Edit. Siglo XXI, Madrid, 1971).

Maxwell, J. C.: «Ethics and Politics in Mandeville», Pbilosopby, 21 (1951), 242.

MAYO, E.: The Human Problems of an Industrial Civilization (The Vicking Press, Nueva York, 1960; 1." ed. americana, 1933).

Mayrl. W. W.: «Ethnomethodology: Sociology Without Society», Catalyst, 7 (1973), 15 y ss.

MenNelL, : «Ethnomethodology and the New "Methodensreit"», Acta Sociológica, 18,4 (1975).

Merton, R. K.: Sociological Ambivalence and other Essays (The Free Press, Nueva York, 1976).

- Social Theory and Social Structure (The Free Press, Glencoe, 1957; hay traducción en el Fondo de Cudtura Económica).

Moya, C.: De la ciudad y de su razón (Cupsa Edit., Madrid, 1977).

Parsons, T.: Structure and Process in Modern Socielies (The Free Press, Glencoe, 1960).

Pascal, B.: Pensées (Losada, Buenos Aires, 1964).

Popper, K.: The Open Society and its Enemies (Routledge and Kegan Paul, Londres, 1962).

- Conjectures and Refutations (Routledge and Kegan Paul, Londres, 1963).

- «The Poverty of Historicism», Economica, XI, 3 (1944), 122.

- Objective Knowledge (Oxford University Press, Londres, 1972).

Price, D. S.: Science Since Babylon (Yale University Press, New Haven, 1961).

Rex, J.: Discovering Sociology (Routledge and Kegan Paul, Londres, 1973).

Rezsorazy, B.: Theorie et critique des faits sociaux (La Rennaissance du Livre, Bruselas, 1971).

Roethlisberger y Dickson: Management and the Worker (Cambridge, Massachussets, 1939).

ROSENBERG, N.: «Mandeville and Laissez-faire», Journal of the History of Ideas, 24 (1963), 183

Ross, A. K. (ed.): Human Bebavior and Social Processes (Houghton Mifflin Co., Bos. ton, 1962).

Runciman, W. G.: A Critique of Max Weber's Pbilosopby of Social Science (Cambridge University Press, Cambridge, 1972).

Ryan, A. (ed.): The Pbilosopby of Social Explanation (Oxford University Press, 1972).

Schineider, L. (ed.): The Scottish Moralists (The University of Chicago Press, Chicago, $1967)$.

- The Sociological Way of Looking at the World (McGraw-Hill Book Co., Nueva York, 1975).

Schurz, A.: Collected Papers-I. The Problem of Social Reality (Martinus Nijhoff, La Hava, 1973).

ScotT, K. J.: «Methodological and Epistemological Individualism», British Journal for the Philosophly of Science, 11 (1961), 331.

Simmel, G.: Sociologia, 1: Estudio sobre las formas de la socialización (Revista de Occidente, Madrid, 1977; 1. ed. alemana, 1908j.

SMITH, A.: The Wealth of Nations (Adam and Charles Black, Edinburgh, 1883). 
Sombart, W.: «Los comienzos de la sociología, en Noosociología (IEP, Madrid, 1962, pp. 17 y ss.; $1 . "$ ed. en 1923).

Stewart, D.: Collected Works (W. Hamilton Ed., Edinburgh, 1854).

Strasser, H.: The Normative Structure of Sociology (Londres, 1976).

SWINGEWOOD, A.: «Origins of Sociology: The Case of the Scottish Enlightment», British Journal of Sociology, XXI, 2 (1970), 64.

Toceueville, A.: La Democracia en América (Fondo de Cultura Económica, México, 1957).

- El antiguo régimen y la revolución (Guadarrama, Madrid, 1969).

Turner, R. H.: "The role and the Person", American Journal of Sociology, 84 (1978), 1. Von Wright, G. H.: Norm and Action (The Humanities Press, Nueva York, 1963).

Von Hayer, F.: Siudies in Pbilosopby, Politics and Economics (Routledge and Kegan Paul, Londres, 1967).

- The Counter-Revolution of Science (The Free Press, Glencoe, 1952).

- New Studies in Pbilosopby, Politics, Economics and the History of Ideas (Routledge and Kegan Paul, Londres, 1978).

Wagar, M.: The Idea of Progress Since the Renaissance (John Wiley and Sons Inc., Nueva York, 1969).

Waring, W. G. (ed.): Deism and Natural Religion (Ungar Pub. Co., Nueva York, 1967).

Weber, M.: La ética protestante y el espiritu del capitalismo (Edit. Península, Barcelona, 1973).

- Essais sur la théorie de la science (París, 1955).

- Economía y Sociedad (Fondo de Cultura Económica, México, 1969).

Whitehead, N.: Science and the Modern World (The Free Press, Nueva York, 1967).

Zimmerman, D. H., y Wieder, D. J.: «Ethnomethodology and the Problem of Order", en J. P. Douglas (ed.), Undersianding Everyday Life (Aldine Pub. Co., Chicago, 1970). 